Kalbar, P., Birkved, M., Karmakar, S., Nygaard, S. E., \& Hauschild, M. Z. (2017). Can carbon footprint serve as proxy of the environmental burden from urban consumption patterns? Ecological Indicators, 74, 109-118. DOI: 10.1016/j.ecolind.2016.11.022

\title{
Can carbon footprint serve as proxy of the environmental burden from urban consumption patterns?
}

Pradip P. Kalbar ${ }^{* \#}$, Morten Birkved ${ }^{1}$, Subhankar Karmakar²,3,4 ${ }^{2}$ Simon Elsborg Nygaard ${ }^{5}$, and

Michael Hauschild ${ }^{1}$

${ }^{1}$ Quantitative Sustainability Assessment Division, Department of Management Engineering, Technical University of Denmark (DTU), Produktionstorvet 424, DK-2800 Kgs. Lyngby, Denmark

${ }^{2}$ Centre for Environmental Scienc

e and Engineering, Indian Institute of Technology Bombay, Powai, Mumbai 400 076, India.

${ }^{3}$ Interdisciplinary Programme in Climate Studies, Indian Institute of Technology Bombay, Mumbai 400076. India.

${ }^{4}$ Centre for Urban Science and Engineering, Indian Institute of Technology Bombay, Powai, Mumbai 400 076, India.

${ }^{5}$ Department of Psychology and Behavioural Sciences, BSS, Aarhus University, Denmark

\# Corresponding author:

Pradip P. Kalbar

Quantitative Sustainability Assessment Division

Dept. of Management Engineering

Technical University of Denmark (DTU)

Produktionstorvet

Building 424, room 231

2800 Kgs. Lyngby

Denmark

Tel. No. +4545254607

Email Address: kalbar@iitb.ac.in; pradipkalbar@gmail.com

Abstract: Carbon footprint (CFP) is widely applied as an indicator when assessing environmental sustainability of products and services. The objective of the present study is to evaluate the validity

\footnotetext{
Present affiliation: Centre for Urban Science and Engineering, Indian Institute of Technology Bombay, Powai, Mumbai 400 076, India
} 
31 of CFP as overall environmental indicator for representing the environmental burden of residents 32 from urbanized areas. Applying four different Life Cycle Impact Assessment (LCIA) methods 33 environmental impact profiles were determined for the consumption patterns of 1281 Danish urban 34 residents. Six main consumption components were distinguished including road transport, air travel, 35 food, accommodation (covering consumption of materials for the construction of dwellings) and use 36 of energy in terms of thermal energy, and electricity. The results for the individual consumption 37 components showed a strong correlation between CFP and nearly all other impact indicators for all the applied LCIA methods. However, upon aggregation of the indicator results across consumption components, the impact indicators for the total consumption showed no significant correlation

40 between CFP and the other impact scores for any of the four impact assessment methods. These findings suggest that while CFP can be a good indicator of the environmental burden associated with specific activities, this is not the case for more complex activities (such as consumption patterns related to urban life styles). This conclusion discourages the use of CFP as sustainability measure in relation to regulation of private or public consumption.

Keywords: Urban resource consumption; carbon footprint; Life cycle assessment; sustainability; urban systems 


\section{Introduction}

The increasing focus on the environmental impacts associated with resource consumption and other anthropogenic activities have led to the development of a multitude of approaches for estimating environmental footprints. Carbon footprint, water footprint, material footprint and energy intensity etc. are some of the approaches used to account for environmental impacts(Čuček et al., 2012; Herva et al., 2011; Singh et al., 2009) assessed in the various footprints. Life Cycle Assessment (LCA) is one of the most widely used and a well-suited tools for quantifying environmental footprints even for complex systems such as systems closely associated with human choices and preferences and hence systems containing subjective elements.

Since the introduction of the methodology, LCA has undergone continuous development and refinement. Rebitzer et al. (2004) and Pennington et al. (2004) both provide exhaustive documentation on the detailed framework of LCA. The LCA field is vast and base on inputs from multiple scientific disciplines such as chemical fate and transport modeling, exposures assessments, effect/damage modeling on ecosystem and human health. Hence, there has been continuous inclusion of new knowledge, concepts and development of methodologies. Finnveden et al. (2009) and Guinée et al. (2011) reported historic and recent developments in LCA as well future requirements and challenges.

Although, the LCA is widely used for assessing products and services there are still unresolved issues, which need to be addressed. Reap et al. (2008a, 2008b) documented some of the unresolved issues in LCA while Udo de Haes et al. (2004) illustrated some of the limitations of LCA. The majority of the issues are related to the disagreement on the common choice of functional unit, system boundary (Suh, 2006; Tillman et al., 1998), allocation methods(Azapagica and Cliftb, 1999; Ekvall and Finnveden, 2001) and LCIA methodologies. Choices made in an LCA relating to one or more of these issues and limitations introduce a subjective element to any LCA and makes generally difficult to compare LCA studies even if conducted on similar products or services.

LCA requires vast amounts of data, software, specialized skills and time all limiting the application of LCA. In addition, the assessment method requires data analyst skills on expert level in order to fully understand and interpret the results provided by an LCA. These complexity challenges posed by the LCA methodology itself and the results here of makes it difficult to communicate LCA based results to the public and stakeholders (Weidema et al., 2008) without introducing simplifying however 
subjective assessment layers such as e.g. weighting and/or an additional damage modelling layer further increasing the assessment uncertainty. No matter if one chooses to apply weighting and/or damage modelling the credibility of an LCA will thus be compromised either due to introduction of subjective elements and/or increased uncertainty.

Due to communication hurdles caused by the complexity of many LCA results, researchers, policy makers, experts, and industries have been looking for a way to bypass weighting and damage modelling in LCA in order to increase the communicability of LCA results. A solution could be a proxy indicator(Huijbregts et al., 2010; Udo de Haes, 2006), a single environmental impact indicator intended to serve as a proxy for all the other possible environmental burdens (and hence also the overall environmental sustainability performance) associated with products, services and technologies.

Various studies have previously explored and attempted to validate the use of single point indicators (including carbon footprint) to represent overall environmental impacts. Bösch et al. (2007) correlated Cumulative Exergy Demand (CExD) indicators with CML 2001 and Ecoindicator (EI) 99 characterization factors for energetic and non-energetic resources and discovered weak or no correlation between these. Bao and Multani (2007) carried out a similar analysis on 47 products (industrial as well as consumer products) where correlations between life time energy consumption and environmental impacts estimated using LCA were explored. The study yielded clear correlation between the life cycle energy consumption and LCA results, for most of the products.

Huijbregts et al. (2010) conducted a comparative assessment of the Cumulative Energy Demand (CED) of 498 commodities (metals, glass, paper and cardboard, organic and inorganic chemicals, agricultural products, construction materials, and plastics) and six frequently applied environmental life cycle assessment based indicators [Ecological Footprint (EF), Cumulative Exergy Extraction from the Natural Environment (CEENE), Carbon Footprint (CFP), Environmental Priority Strategy (EPS), Ecological Scarcity (ES) and Eco-Indicator 99 (EI 99)]. The study found that CED produces comparable ranking of commodity production impacts compared to all other methods included in the study. The authors further argued that CED could be used as a screening indicator for environmental performance at early product development stages. However, the study also points out that CED may not be a good choice for agricultural products where environmental impacts also are closely associated with non-energy related emissions (e.g. pesticides, nutrients). 
Berger and Finkbeiner (2011) analyzed correlations between energy and resource consumption based impacts across a multitude of indicators for 100 materials (ores, metals, alloys monomers and polymers, organic intermediates, inorganic intermediates). The study highlighted that there was no significant correlation between indicators assessing resource consumption (i.e. scarce resources, water, land etc.) and pollution driven impacts (toxic impacts categories, eutrophication etc.). The study further suggests that a wide range of impacts need to be evaluated comprehensively in order to appropriately quantify the impacts related to resource consumption. However, a significant correlation was found among resource consumption indicators suggesting a possibility of reducing/aggregating resource consumption dedicated indicators for defining resource use and hence simplifying the LCA result set.

Laurent et al. (2010) investigated the use of CFP as overall environmental performance indicator by correlating CFPs with Human Toxicity (HT) impact potentials for selected material production unit processes. The study concludes that HT impacts are not significantly correlated with CFPs and further that the CFP-HT dependencies appear to be material (metallic or non-metallic) specific. The same approach of exploring correlations was further extended in another study to analyze a more diverse and considerable dataset (3954 impact profiles) of products/services(Laurent et al., 2012). This study concluded that CFP may correlate at the overall environmental impacts of mixed products/services; however, a deeper investigation of specific product/service categories did not confirm the correlation between the CFP and environmental impacts (Laurent et al., 2012). This observation led to general recommendations on when CFP may be appropriate and when it cannot be considered appropriate as overall environmental performance indicator. The study recommends that unless CFP has been proven well correlated with other environmental impacts of a given product/service (group) it has to be regarded as a transition (i.e. uncertain) indicator.

In the food sector, Röös et al. (2013) evaluated the use of CFP to represent the overall environmental impacts from animal-rearing and found that the environmental impacts of meat from monogastric animals can be well represented by CFP. However, the study also reported that the same is not the case for meat production from ruminants. Rugani et al. (2013) presents a comprehensive review of CFP studies within the wine sector and recommends that further studies need to be undertaken in order to understand the complex market interactions associated with the entire product system of wine. The complex value chain of wine and associated market interactions makes it dubious to recommend the use of CFP as a proxy environmental performance indicator for this sector. 
Although the above studies partly shows significant and partly insignificant correlations between CFP and other single point indicators. One issue that appears to tie the above studies together is that when using proxy indicators for representing the overall performance of systems and services, in many cases there is a considerable chance that CFP or other proxy indicators poorly correlated with the overall environmental performance. As examples here of Finkbeiner (2009) presents a multitude of such examples where use of carbon footprint as a proxy indicator is invalid.

The aim of the present work is to assess whether CFP can be used as a proxy environmental performance indicator for the diverse set of products and services related to private consumption. The assessment is based on analysis of consumptions patterns for 1281 urban Danish residents. Detailed results from a comprehensive Personal Metabolism (PM) - LCA study of the 1281 consumption patterns are reported in Kalbar et al. (2016).

\section{Methodology}

The present study is based on the results obtained from a coupled PM - LCA model presented in detail in Kalbar et al. (2016). PM-LCA model is a specific type of consumer/lifestyle LCA(Hellweg and Milà i Canals, 2014), where rather than focusing on city or country scale consumptions (Goldstein et al., 2013), consumption patterns at individual levels are assessed. The PM-LCA model was used to assess and quantify the impacts related to consumption patterns of urban Danish residents across the entire value chain from the cradle to the grave of the goods being consumed. The model is based on the outcome of a questionnaire survey analyzing the purchase and utilization of commercial goods and services among urban Danish residents. The survey data covers accommodation, energy (thermal energy and electricity), road transportation, air travel, food consumption, and expenditures related to products and services. In addition to the consumption, recycling habits and related sustainability behavioral factors were compiled via the questionnaire. In total, 1281 respondents (questionnaire filled completely) were assessed as part of the study.

Annual household consumption patterns were estimated using the basic data compiled from the completed and returned questionnaires which again were used to parameterize the generic PM model capable of modelling all 1281 household consumption scenarios. The elementary flows associated with the consumption scenarios were modelled and the associated environmental impacts quantified with LCA. The standard one-family house was modelled in Gabi 6.0 (using Ecoinvent 2.2 database) 
covering production of all building materials required for the construction of house. Standard unit processes available in Gabi 6.0 (via Ecoinvent 2.2 database) on thermal energy (heat), electricity, road transport (various fuel types and Euro standards for private cars and public buses and trains) and air travel were used to compute impact potentials related with thermal energy, electricity, road transport and air travel utilization in households. For estimation of the impacts associated with food consumption, Simapro 8.0.4 (with Ecoinvent 3.1 database) was used. Four impact assessment methods EDIP97 (Hauschild et al., 1998; Wenzel et al., 1997), EI 99(Goedkoop and Spriensma, 2001), CML 2001 Baseline(Guinée et al., 2001) and ReCiPe 2008(Goedkoop et al., 2008) were selected for the LCIA. The impact potentials for each component of consumption (accommodation, thermal energy, electricity, road transport, air travel and food) were estimated separately along with the impact potential of the total consumption scenario.

The climate change impact potential assessed according to the ReCiPe 2008 impact assessment methodology [henceforth called Carbon FootPrint (CFP)] was considered as an independent variable, and regression analyses were performed against the remaining 16 mid point indicators (water depletion was not considered due to unavailability of normalization reference), 3 end point indicators and one aggregated single score obtained applying the ReCiPe 2008 methodology, the 11 midpoint indicators and one aggregated total score obtained applying the CML 2001 Baseline methodology, the 3 endpoint indicators and one aggregated total score obtained applying the Ecoindicator 99 methodology, and the 11 indicators and one aggregated total score obtained applying the EDIP97 methodology (refer to Figure 1). Overall total 38 midpoint indicators, 6 endpoint indicators and 4 single score indicators were used for regression analyses (in total 48 regression analyses were conducted, refer to Table 1). For all the mid-point indicators normalized values were used for regression. The normalized values, endpoints and single or total scores were obtained using themost context relevant normalization and weighing factors considering hierarchical perspective where available. To obtain a total score in accordance with the CML 2001 Baseline method a set of weighting factors from Gabi 6.0 were used(PE International, 2012).

The approach used to analyze correlations among the CFP and other indicators across the different consumption components and total consumptions is presented in Figure 1. To derive all possible linear, nonlinear and partial correlations among CFP and the other impact indicators for individual and total consumption patterns, both parametric and nonparametric correlation analyses were conducted. Linear correlation structures were captured through Pearson correlation coefficient 
201 and coefficient of determination $\left(\mathrm{R}^{2}\right)$, while nonlinear correlation structures were analyzed with 202 nonparametric rank based coefficients, Spearman's rho $(\rho)$ and Kendall's tau $(\tau)$ (Berthouex and 203 Brown, 1994; Chen and Popovich, 2002; Reimann et al., 2011). All the correlation coefficients were 204 derived and their statistical significance were assessed for evaluation of the association between the 205 CFP and all the additional midpoint, endpoint and single score indicators (in total 48) obtained 206 applying the four LCIA methods considered for each of the consumption components and for the total 207 consumption scenario. All the computations were carried out using MATLAB ${ }^{\circledR}$ R2013b version 208 8.2.0.701.

209 As shown in Figure 1, the correlation coefficients between CFPs of each consumption component 210 along with additional 48 method specific indicators were obtained. In addition the simple and partial 211 for both linear and nonlinear correlation coefficients between the CFPs of total consumption and the 212 remaining 48 indicators of total consumption were also analyzed. Simple correlation coefficients 213 (both parametric and nonparametric) are not sufficient to explain relationships between indicators 214 particularly when causal relations are suspected among variables or indicators. Use of partial 215 correlation coefficients is an alternative, where the partial or net correlation represents actual association of two analyzed indicators eliminating the effect of the remaining indicators (Spiegel and Stephens, 2007). The partial correlation coefficient between CFP and any other impact indicator should thus be interpreted as a particular conditional correlation coefficient; which is basically a correlation between these two indicators conditioned on the set of remaining indicators.

As a final analysis, a set of interdependency analyses was carried out in order to assess the correlations among the selected indicators for the considered consumption components assessed. Four ReCiPe indicators (carbon footprint, freshwater eutrophication, terrestrial ecotoxicity, human toxicity) were selected to validate the interdependency among the indicators. As an example the interdependency analysis for correlation of CFP of Electricity with CFP of road transport components are highlighted in Figure 1. 


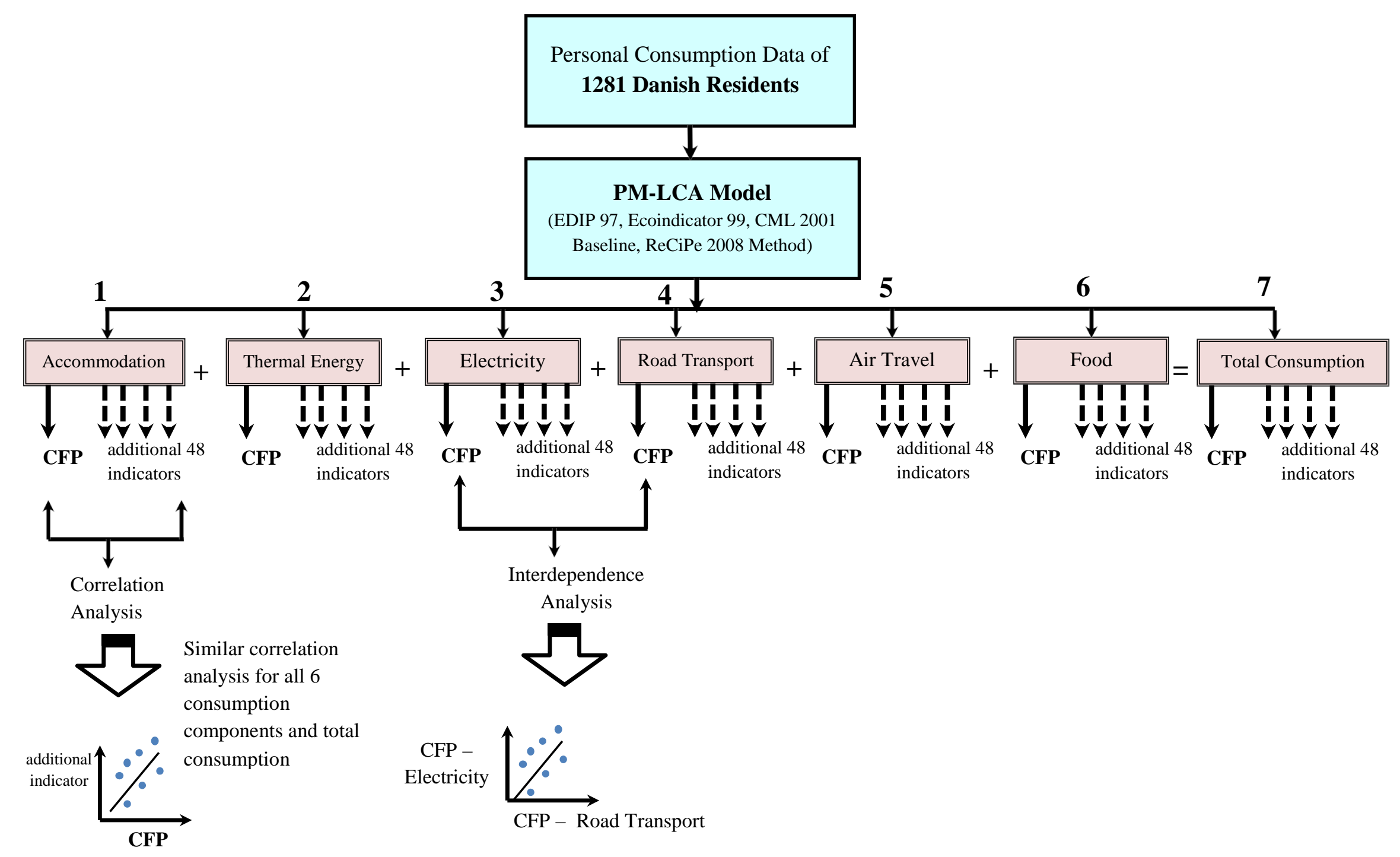


229 The results obtained from the four types of regression analyses on the total consumption patterns are 230 presented in Table 1 . The correlation graphs for all the 48 indicators quantified for the total 231 consumption pattern are in Figure 2. Table S1 in the Supporting Information (SI) provides detailed correlation results obtained for all six consumption components along with total consumption pattern results. From the results presented in Tables 1 and S1, it is observed that the linear correlation values captured by $R^{2}$ follow the patterns similar to nonlinear correlation structures, obtained through Spearman's $(\rho)$ and Kendall's $(\tau)$ correlation coefficients. In nonparametric correlation analysis, Spearman's rank correlation coefficient usually gives higher values than Kendall's rank correlation when sufficiently large and consistent data is available for analysis.(Chen and Popovich, 2002; Reimann et al., 2011) Similar observation has been made in our results as the dataset considered in the current analysis is sufficiently large and consistent. These observations indicate that linear correlation is predominant in the dataset in which the outliers are not affecting the correlation. Hence, only $R^{2}$ values were used for further analysis and discussions.

242 The results summarized in Table S1, indicate that the CFP of each consumption component correlates very well with all the other 48 indicators quantified for each of the consumption components: accommodation, thermal energy, electricity, road transport, air travel and food. However, when the results for the individual consumption components are aggregated to obtain the total impacts for the entire consumption pattern, the CFP values for the entire consumption patterns do not necessarily correlate well with all the 48 additional indicators also quantified for total consumption (refer to Table 1). Upon closer inspection of the results obtained from the correlation analyses of the indicators quantified for the entire consumption patterns (Table 1), it is observed that the correlation between the CFP is strong ( $R^{2}$ in the range of 0.80 to 0.90 ) for the resource depletion, fossil depletion, ozone depletion, particulate matter formation and photochemical oxidant formation indicators irrespective of the impacts assessment method applied. 


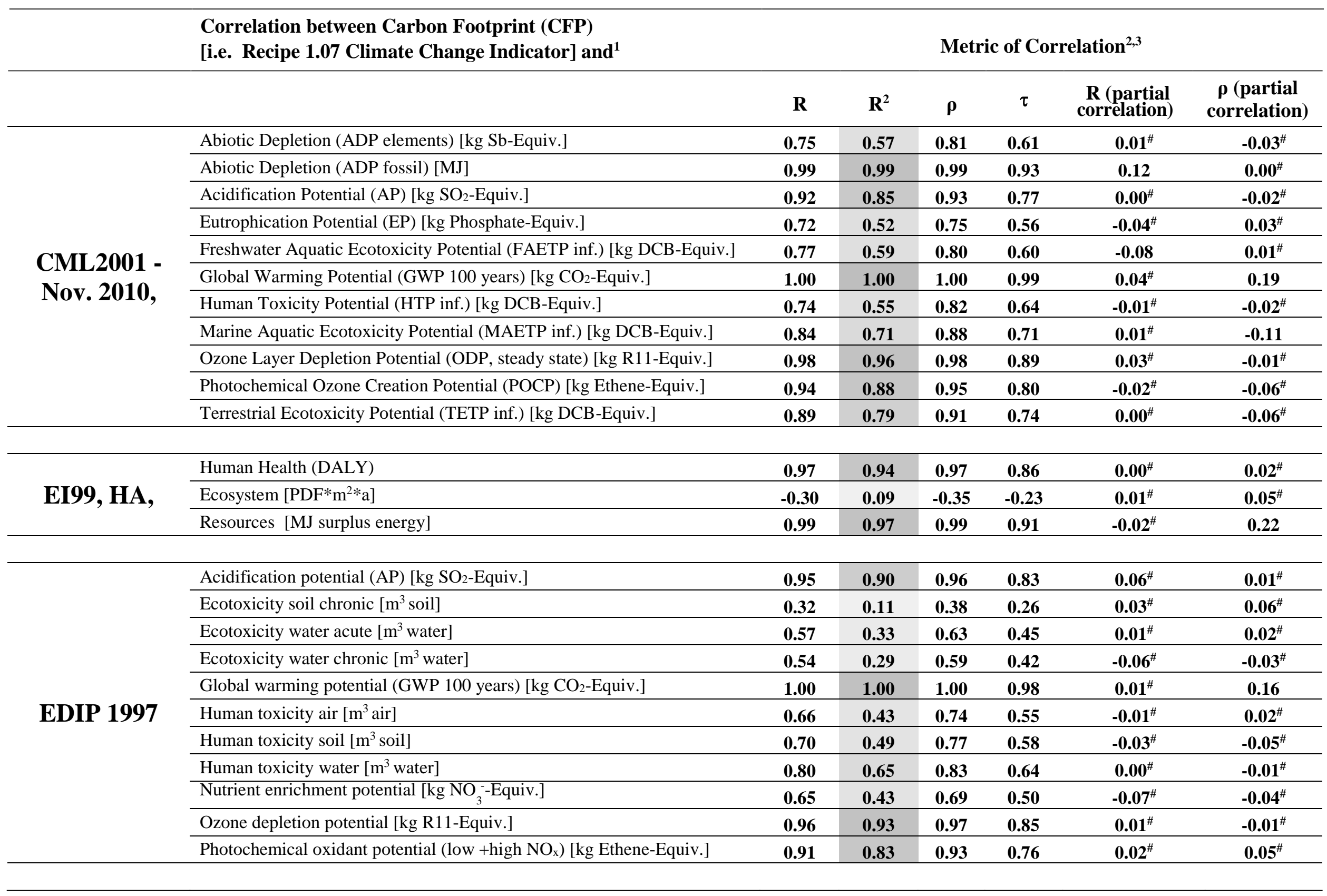


Correlation between Carbon Footprint (CFP)

[i.e. Recipe 1.07 Climate Change Indicator] and ${ }^{1}$

Metric of Correlation ${ }^{2,3}$

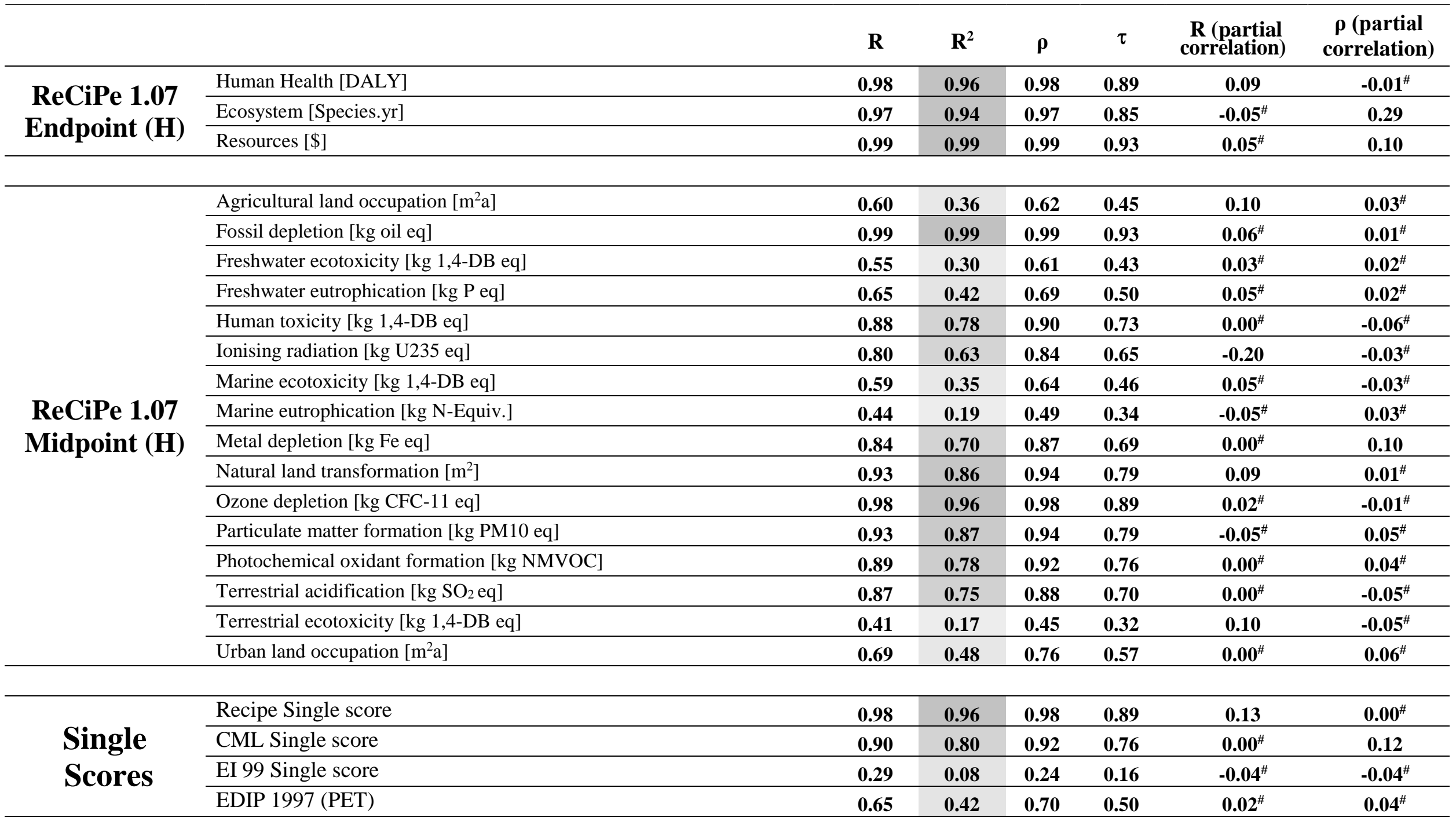

${ }^{1}$ Normalized values were used for correlation analysis (units of indicators are provided only for better understanding of version of the LCIA method and respective indicators used) ${ }^{2}$ Pearson Correlation Coefficient $(R)$ and Coefficient of Determination $\left(R^{2}\right)$, Sperman's rho rank correlation coefficient $(\rho)$ and Kendall's tau rank correlation coefficient $(\tau)$ ${ }^{3} R^{2}$ values are grey color shaded according to higher to lower values (more the value more the intensity of grey shade)

\#indicates the correlation not significant at 0.01 level. 

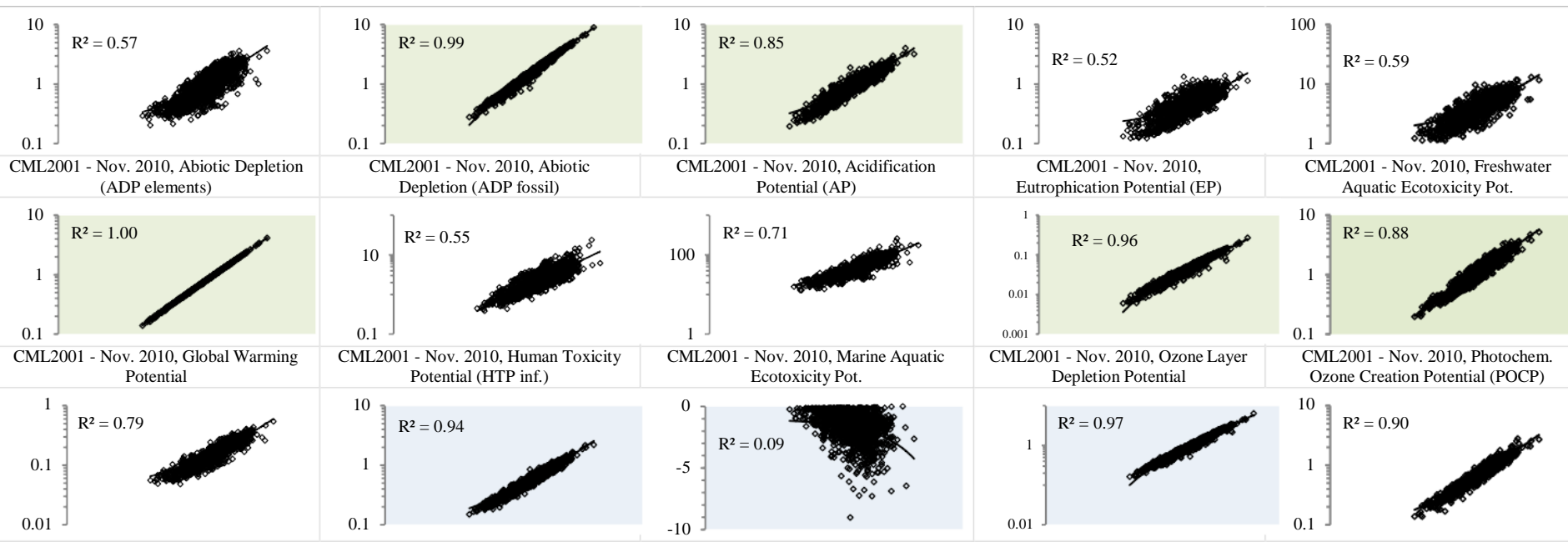

CML2001 - Nov. 2010, Human Toxicity

CML2001 - Nov. 2010, Marine Aquatic

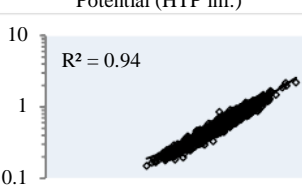

CML2001 - Nov. 2010, Terrestric Ecotoxicity Potential

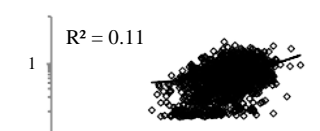

0.01

EI99, HA,Human Health

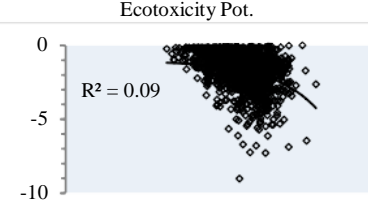

EI99, HA, Ecosystem

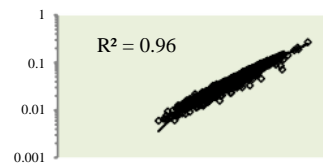

CML2001 - Nov. 2010, Ozone Layer Depletion Potential

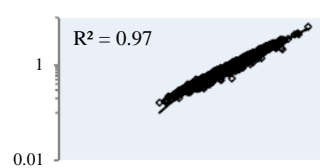

EI99, HA, Resources

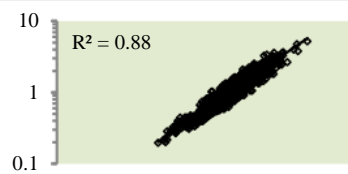

CML2001 - Nov. 2010, Photochem. Ozone Creation Potential (POCP)
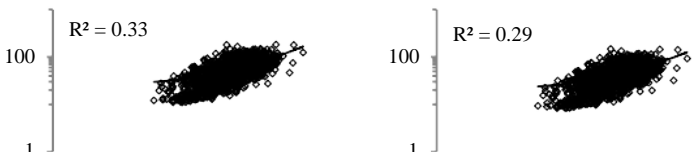

EDIP 1997, Ecotoxicity water acute
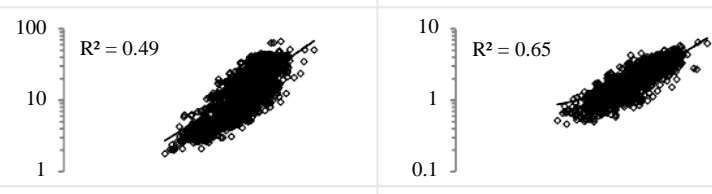

EDIP 1997, Ecotoxicity water chronic

EDIP 1997, Human toxicity soil

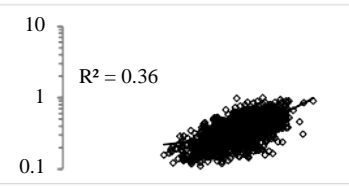

EDIP 1997, Human toxicity water

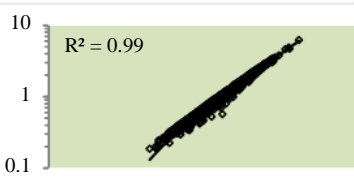

ReCiPe 1.07 Midpoint (H) - Agricultural land occupation

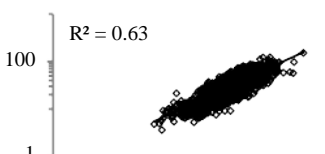

ReCiPe 1.07 Midpoint (H) - Ionising radiation

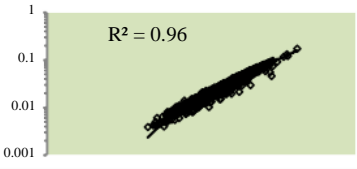

ReCiPe 1.07 Midpoint (H) - Ozone depletion

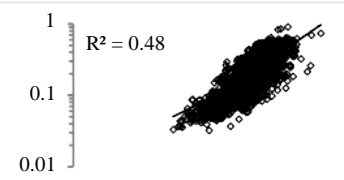

ReCiPe 1.07 Midpoint (H) - Urban land occupation

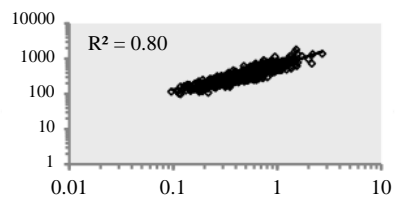

CML Single Score depletion

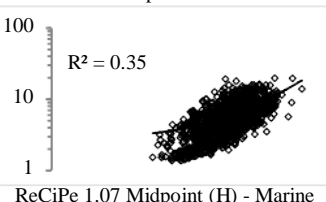

ecotoxicity

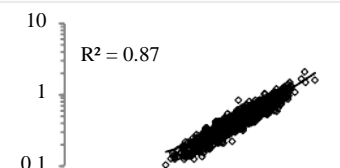

ReCiPe 1.07 Midpoint (H) - Particulate matter formation
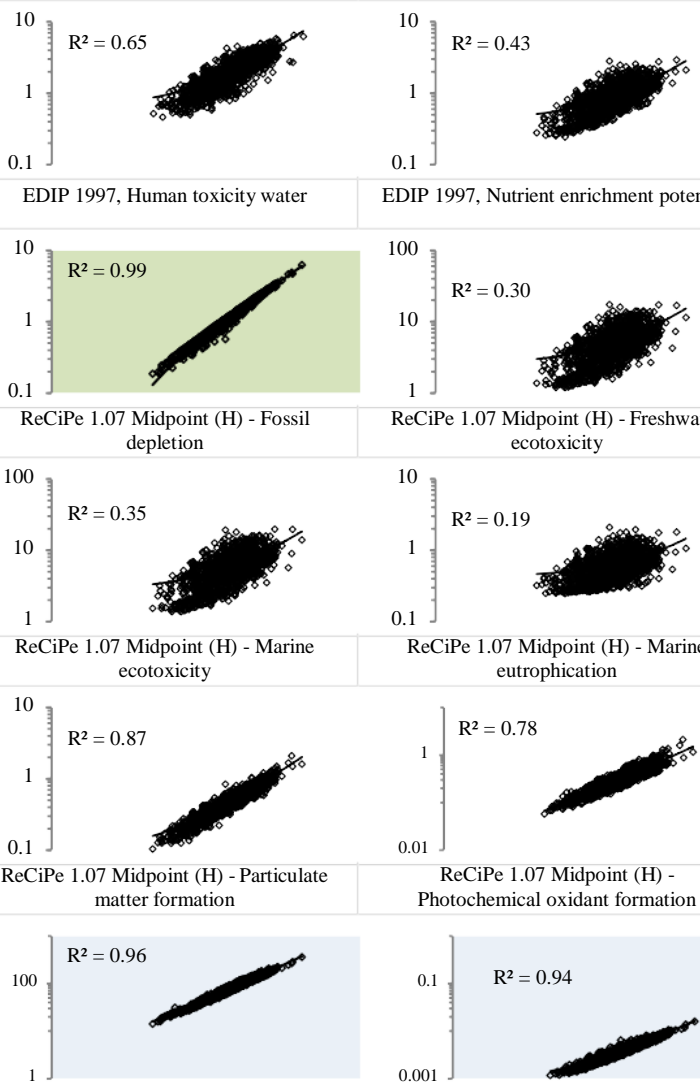

EDIP 1997, Nutrient enrichment potential
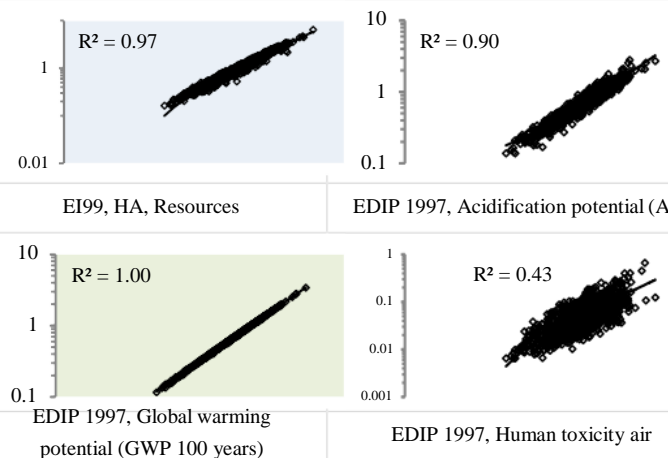

EDIP 1997, Acidification potential (AP)

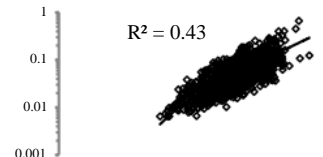

EDIP 1997, Human toxicity air

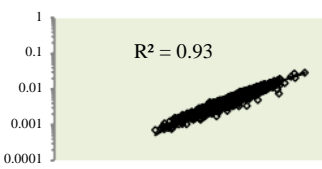

EDIP 1997, Ozone depletion potential

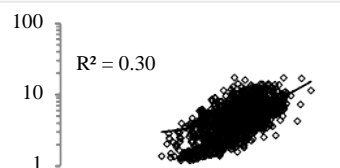

ReCiPe 1.07 Midpoint (H) - Freshwater ecotoxicity

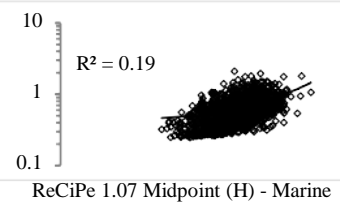
eutrophication
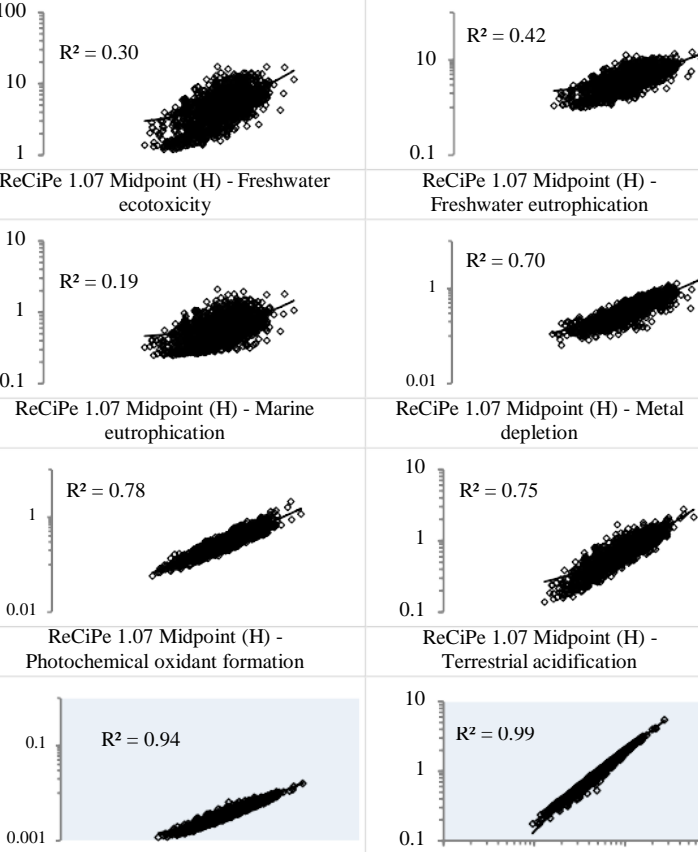

ReCiPe 1.07 Midpoint $(\mathrm{H})$ -
Freshwater eutrophication

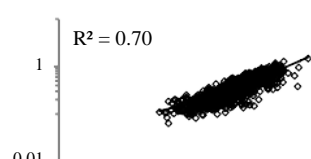

ReCiPe 1.07 Midpoint (H) - Metal

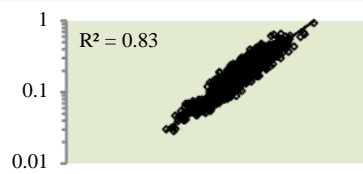

EDIP 1997, Photochemical oxidant potential

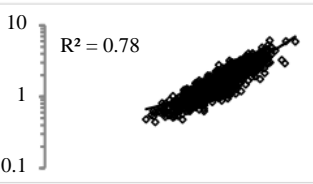

ReCiPe 1.07 Midpoint (H) - Human toxicity

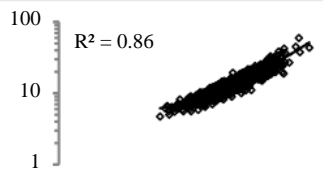
depletion

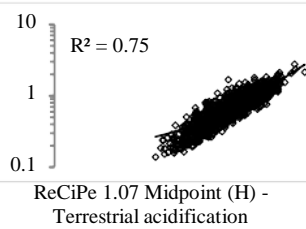

ReCiPe 1.07 Midpoint (H) - Natural land transformation

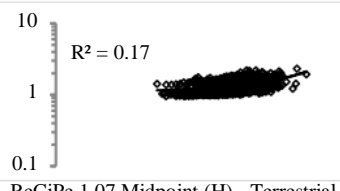

ReCiPe 1.07 Midpoint (H) - Terrestrial ecotoxicity
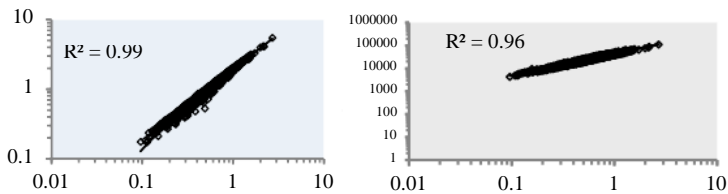

ReCipe 1.07 Endpoint (H) Resources Recipe Single score
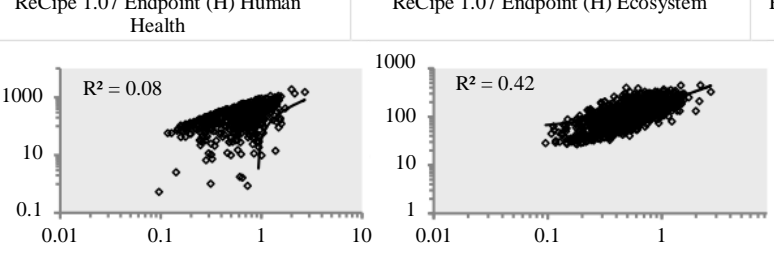

Figure 2: Correlation graphs for CFP against each of the other 48 indicators quantified for the total consumption pattern (refer to Table 1). The x-axes of each graph are ReCiPe CFP and the individual y-axes are the other indicator mentioned below each of the graphs. Pls. note that a double logarithmic plot has been used for all the correlations, except for EI99, HA, Ecosystem. Green color shaded plots represent midpoints, which all correlates strongly with CFP. Blue color shaded plots are correlations explorations between CFP and various endpoints whereas grey color plots are correlations explorations between CFP and single scores. 
265 The correlations obtained for the ReCiPe CFP and the midpoint indicators quantified for the entire 266 consumption patterns for impacts on ecosystems toxicity related impacts such as aquatic ecotoxicity, 267 marine ecotoxicity, terrestrial ecotoxicity as well as human toxicity, marine and fresh water 268 eutrophication and land occupation were found to be weak ( $R^{2}$ in the range of 0.10 to 0.50$)$. Further 269 as presented in Table 1, it was found that the correlation between the CFP and the endpoint indicators 270 obtained for the entire consumption pattern applying the Ecoindicator 99 and ReCiPe 2008 methods 271 was strong ( $R^{2}$ range 0.89 - 0.99), except for the ecosystem endpoint of the Ecoindicator 99 method. 272 The results of correlation analyses between the ReCiPe CFP and the aggregated single scores 273 quantified for the entire consumption patterns from the four impact assessment methods revealed that 274 only the single score obtained applying the ReCiPe 2008 method exhibited strong correlation with 275 the ReCiPe CFP. The last two columns of Table 1 showed Pearson's (parametric estimate to quantify 276 linear correlation) and Spearman's (nonparametric estimate to quantify nonlinear correlation) partial 277 correlation coefficients, which showed that most of the partial correlation values were insignificant at 0.01 level (marked with \# sign), which gave better insight in individual association of all indicators with CFP, eliminating the effects of remaining indicators in terms of latent association or interdependence among them. Hence the results from partial correlation analysis assured that the CFP indicator alone does not carry the information which remaining 48 indicators carry.

282

\section{Discussion}

The impacts associated with the consumption components for accommodation (construction of house), thermal energy, electricity, road transport (cars, bus and trains), air travel and food consumption as well as the entire consumption pattern representing the sum of the consumption components were accounted for, applying a multitude of unit processes (industrial system processes, energy production processes, transportation and agricultural processes) in order to model the PM systems applying an LCA approach.

The strong correlations between the ReCiPe CFP and the 48 additional indicators within the individual consumption components (refer to Table S1) would suggest that CFP is usable as a proxy impact indicator for the individual consumption components covering consumption of commercial goods and services. However, the moment that the consumption components are aggregated into a full consumption pattern, the correlation is poor both for simple and partial correlation analyses (see 
295 also Table 1). The aggregation of consumption components involves aggregation of impacts across different sectors such as e.g. the construction and agriculture sectors. To investigate the loss of correlation upon aggregation of the consumption component, an interdependence analysis among all indicators of individual consumption components was conducted. The correlation of impact indicators among the individual and aggregated consumption components was analyzed for four selected ReCiPe impact potentials (Climate change, Freshwater eutrophication, Terrestrial ecotoxicity and Human toxicity). The results ( $\mathrm{R}^{2}$ values) of the correlation analysis covering climate change, freshwater eutrophication, terrestrial ecotoxicity and human toxicity are presented in Table 2. The detailed results from all four types of correlation coefficients $\left(R, R^{2}, \rho, \tau\right)$ are provided in Table S2 in the SI.

The result of interdependence study reveals that none of the indicators shows correlation to itself across individual consumption components and can hence be regarded as totally independent (most $R^{2}$ values between 0 to 0.2 ). Hence, although there is a strong correlation found between CFP and 48 indicators for each of the consumption components (refer to Table S1), no considerable correlation was observed upon aggregation of the results across consumption components in order to account for the entire consumption pattern (refer to Table 1).

The reason behind this phenomenon we seek to explain in Figure 3, where the correlation graphs for climate change versus fresh water ecotoxicity (FET) are shown for each of the individual consumption components and for the entire consumption pattern. As illustrated in the figure CFP correlate very well with FET for all 1281 results for each of the individual components, $\left(R^{2}\right.$ is close to 1.00 for all consumption components). However, the slopes of the correlation graphs are different, ranging from less than 1 from thermal energy and air travel to nearly 50 for food, in accordance with the independence of the individual consumption components that was also demonstrated in the interdependence study in Table 2. Hence, when the results for the consumption components are aggregated to give the entire consumption pattern, a new and much weaker correlation emerges between CFP and FET (with $R^{2}=0.30$ ). Similar correlation graphs for CFP versus five additional ReCiPe indicators representing rather different types of environmental impact (Terrestrial ecotoxicity, Human toxicity, Ozone depletion, Fossil depletion, Freshwater eutrophication) for individual consumption components as well as the entire consumption pattern are presented in Figure S1. Together these results support the observation that although there may exist significant correlation between CFP and an environmental impact indicator at the level of an individual consumption 
component, at the aggregation level totally new correlation situation occurs. The relation between CFP and other impact indicators typically gets weaker with increasing complexity of the consumption pattern.

These findings are in agreement with other recent efforts on correlating CFP with other impact indicators. Strong correlation among some of the midpoints (resource depletion, fossil depletion, ozone depletion, particulate matter formation and photochemical oxidant formation ) and CFP has also been reported by e.g. Van Hoof et al. (2013). The reason for these strong correlations is explained by the energy use across the supply chain and the interdependency of the indicators meaning that improvement in one indicator in this group is accompanied by improvement in another indicator in the group.

The strong correlation observed between CFP and other impact indicators at the level of individual consumption components may be attributed to a dominating contribution of one or a few specific unit processes within each of the modelled consumption components. For example, although a wide range of processes contribute to the overall impact potential originating from the construction of a house, it is the production processes of aluminum window frames, concrete and steel that accounts for about $55-60 \%$ of the impacts in the climate change impact category, $70-75 \%$ of the human toxicity, fresh water ecotoxicity, marine ecotoxicity, freshwater eutrophication impact categories and 55\% of the impact potential in the terrestrial ecotoxicity impact category. The impacts from these three production processes are all driven by their consumption of large amounts of resources and energy (the latter of which is mainly generated from combustion of fossil fuels). Previous work has demonstrated a significant correlation between CFP and other indicators for the metal and energy production processes (fossil as well as some renewable energy processes).(Laurent et al., 2012) Such significant correlation between CFP and other indicators translates into the observed correlations in this study the unit process or component level of the construction of house, as the impacts are tied to metal and energy production. 
352 Table 2: Result of interdependence study - correlation among indicators of each consumption component

\begin{tabular}{|c|c|c|c|c|c|c|c|c|c|}
\hline & & & & & ecipe 1.07 & limate $\mathrm{Ch}$ & nge Indica & & \\
\hline & & & 1 & 2 & 3 & 4 & 5 & 6 & 7 \\
\hline \multirow{8}{*}{ 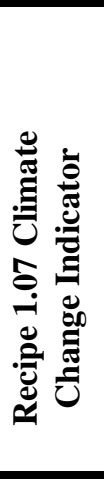 } & $\begin{array}{c}\begin{array}{c}\text { Correlation } \\
\text { between }\end{array} \\
\end{array}$ & & $\begin{array}{c}\text { Accommod } \\
\text { ation }\end{array}$ & $\begin{array}{r}\text { Thermal } \\
\text { Energy } \\
\end{array}$ & Electricity & $\begin{array}{c}\begin{array}{c}\text { Road } \\
\text { Transport }\end{array} \\
\end{array}$ & Air Travel & Food & $\begin{array}{c}\text { Total } \\
\text { Consumption } \\
\end{array}$ \\
\hline & Accommodation & \multirow{7}{*}{$R^{2}$} & 1.00 & 0.31 & 0.19 & 0.01 & $0.00^{\#}$ & $0.00^{\#}$ & 0.34 \\
\hline & Thermal Energy & & & 1.00 & 0.12 & $0.00^{\#}$ & $0.00^{\#}$ & 0.02 & 0.45 \\
\hline & Electricity & & & & 1.00 & 0.02 & $0.00^{\#}$ & $0.01^{\#}$ & 0.26 \\
\hline & Road Transport & & & & & 1.00 & $0.00^{\#}$ & 0.04 & 0.31 \\
\hline & Air Travel & & & & & & 1.00 & $0.00^{\#}$ & 0.15 \\
\hline & Food & & & & & & & 1.00 & 0.10 \\
\hline & $\begin{array}{c}\text { Total } \\
\text { Consumption }\end{array}$ & & & & & & & & 1.00 \\
\hline \multirow{9}{*}{ 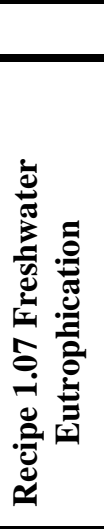 } & & & \multicolumn{7}{|c|}{ Recipe 1.07 Freshwater Eutrophication } \\
\hline & $\begin{array}{c}\begin{array}{c}\text { Correlation } \\
\text { between }\end{array} \\
\end{array}$ & & $\begin{array}{c}\text { Accommod } \\
\text { ation }\end{array}$ & $\begin{array}{l}\text { Thermal } \\
\text { Energy } \\
\end{array}$ & Electricity & $\begin{array}{c}\text { Road } \\
\text { Transport } \\
\end{array}$ & Air Travel & Food & $\begin{array}{c}\text { Total } \\
\text { Consumption } \\
\end{array}$ \\
\hline & Accommodation & \multirow{7}{*}{$R^{2}$} & 1.00 & 0.31 & 0.19 & 0.01 & $0.00^{\#}$ & $0.00^{\#}$ & 0.12 \\
\hline & Thermal Energy & & & 1.00 & 0.12 & $0.00^{\#}$ & $0.00^{\#}$ & 0.02 & 0.10 \\
\hline & Electricity & & & & 1.00 & 0.01 & $0.00^{\#}$ & $0.00^{\#}$ & 0.13 \\
\hline & Road Transport & & & & & 1.00 & $0.00^{\#}$ & 0.03 & 0.22 \\
\hline & Air Travel & & & & & & 1.00 & $0.00^{\#}$ & 0.00 \\
\hline & Food & & & & & & & 1.00 & 0.80 \\
\hline & $\begin{array}{c}\text { Total } \\
\text { Consumption }\end{array}$ & & & & & & & & 1.00 \\
\hline \multirow{9}{*}{ 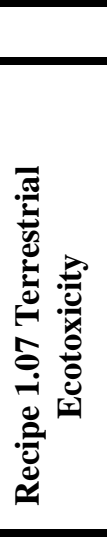 } & & & \multicolumn{7}{|c|}{ Recipe 1.07 Terrestrial Ecotoxicity } \\
\hline & $\begin{array}{c}\text { Correlation } \\
\text { between }\end{array}$ & & $\begin{array}{c}\text { Accommod } \\
\text { ation }\end{array}$ & $\begin{array}{c}\text { Thermal } \\
\text { Energy } \\
\end{array}$ & Electricity & $\begin{array}{c}\text { Road } \\
\text { Transport } \\
\end{array}$ & Air Travel & Food & $\begin{array}{c}\begin{array}{c}\text { Total } \\
\text { Consumption }\end{array} \\
\end{array}$ \\
\hline & Accommodation & \multirow{7}{*}{$R^{2}$} & 1.00 & 0.31 & 0.19 & 0.01 & $0.00^{\#}$ & 0.01 & 0.03 \\
\hline & Thermal Energy & & & 1.00 & 0.12 & $0.00^{\#}$ & $0.00^{\#}$ & 0.02 & 0.04 \\
\hline & Electricity & & & & 1.00 & 0.02 & $0.00^{\#}$ & $0.00^{\#}$ & 0.03 \\
\hline & Road Transport & & & & & 1.00 & $0.00^{\#}$ & 0.06 & 0.10 \\
\hline & Air Travel & & & & & & 1.00 & $0.00^{\#}$ & $0.00^{\#}$ \\
\hline & Food & & & & & & & 1.00 & 0.97 \\
\hline & $\begin{array}{c}\text { Total } \\
\text { Consumption }\end{array}$ & & & & & & & & 1.00 \\
\hline & & & & & Recipe & .07 Huma & Toxicity & & \\
\hline \multirow{8}{*}{ 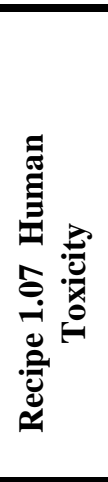 } & $\begin{array}{c}\text { Correlation } \\
\text { between }\end{array}$ & & $\begin{array}{c}\text { Accommod } \\
\text { ation }\end{array}$ & $\begin{array}{c}\text { Thermal } \\
\text { Energy }\end{array}$ & Electricity & $\begin{array}{c}\text { Road } \\
\text { Transport } \\
\end{array}$ & Air Travel & Food & $\begin{array}{c}\text { Total } \\
\text { Consumption } \\
\end{array}$ \\
\hline & Accommodation & \multirow{7}{*}{$R^{2}$} & 1.00 & 0.31 & 0.19 & 0.01 & $0.00^{\#}$ & $0.00^{\#}$ & 0.33 \\
\hline & Thermal Energy & & & 1.00 & 0.12 & $0.00^{\#}$ & $0.00^{\#}$ & 0.02 & 0.21 \\
\hline & Electricity & & & & 1.00 & 0.01 & $0.00^{\#}$ & $0.00^{\#}$ & 0.31 \\
\hline & Road Transport & & & & & 1.00 & $0.00^{\#}$ & 0.04 & 0.49 \\
\hline & Air Travel & & & & & & 1.00 & $0.00^{\#}$ & 0.01 \\
\hline & Food & & & & & & & 1.00 & 0.29 \\
\hline & $\begin{array}{c}\text { Total } \\
\text { Consumption }\end{array}$ & & & & & & & & 1.00 \\
\hline
\end{tabular}

354 \#indicates the correlation is not significant at 0.01 level 


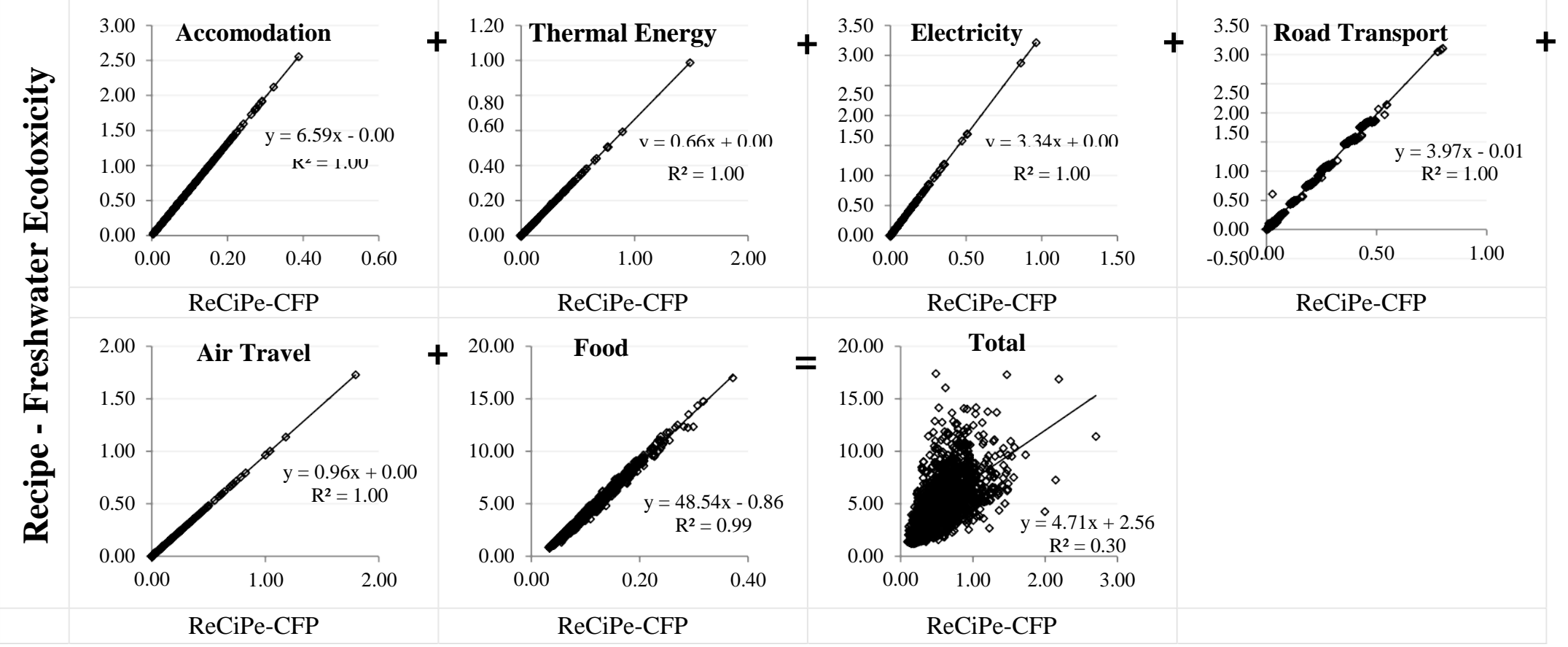

Figure 3: Correlation graphs showing effect of aggregation on the correlation between CFP and Freshwater Ecotoxicity (FET) at the total consumption 
At the aggregation level of the entire consumption pattern the complexity of the modelled product systems increases considerable and the correlations between the different impact indicators thus gets weaker and in some cases even is lost for many impact categories. These observations are illustrated in Figure 3 and Figure S1. Nevertheless, it was shown that significant correlations still exist between CFP and endpoints as well as between CFP and most of the aggregated single scores obtained from four different LCIA methods (refer to Table 1). Particularly, significant correlation is observed between CFP and the ReCiPe endpoints as well as the ReCiPe single score. Analysis of the correlations between midpoint impact categories reveals that, the impact categories accounting for impacts related to agriculture land occupation, human toxicity, ecotoxicity (freshwater and terrestrial), eutrophication (freshwater and marine) all exhibit poor correlation with CFP, which is in alignment with findings from previous studies (Laurent et al., 2012, 2010; Van Hoof et al., 2013). One of the reasons why this weak correlation is not observed in the endpoint results is most likely the poor representation of these midpoint impacts in the damage modelling approach applied by the ReCiPe method meaning that the endpoint results are dominated by the climate change impacts and hence correlate well with CFP. Van Hoof et al. (2013) discussed the issues related with indicator selection in LCA and concluded that endpoint indicators may not always be suitable for providing suitable decision support, and in a recent analysis of LCIA methods and development of recommendations of good practice, none of the endpoint methods were deemed mature for recommendation by the European Commission (Hauschild et al., 2013). Therefore, it is recommended by Van Hoof et al. (2013) to conduct contribution analyses of midpoints contribution to endpoints and based on this analysis identify the midpoints that contribute most to the endpoints. The midpoints identified are then the midpoints to be chosen for decision support and policymaking based on simplified LCA result sets is warranted. The risk associated with the use of CFP as a proxy environmental impact indicator was also highlighted by Röös et al. (2013) in relation to assessment of meat production from ruminants.

One of the limitations of our study is that water depletion indicator was not included in the assessment due to unavailability of normalization reference implemented in the software used to derive the indicators. This limitation actually stems from the LCIA methods such as ReCiPe that have not provided the normalization references for water depletion impact category. Recently, Benini et al. (2014) reported normalization references for the water depletion impact category. However, use of water depletion impacts are not well modelled in the present LCIA methods (Hauschild, et al., 2013) and different software differ in terms implementation extent and approach of characterization factors 
for water depletion (Benini et al., 2014). Adding water depletion impacts to our study would simply add further uncertainty to the results. Also, we do not envisage any major effects of the omission of water depletion indicators on the conclusions drawn from the present analysis, as we have covered a sufficient number and hence diverse set of indicators (agriculture land occupation, human toxicity, ecotoxicity (freshwater and terrestrial), eutrophication (freshwater and marine)) to support our findings on which our conclusions have been drawn.

Our study, which targets assessment of urban consumption and related impact potentials, showed that CFP alone obviously cannot be used as a proxy for the overall environmental footprint in relation to assessment of complex (i.e. systems where the impacts are not driven by a few activities like consumption of energy and/or a narrow palette of resources) product systems involving a multitude of industrial sectors. This finding opposes the use of CFP as environmental performance indicators for complex systems such as urban systems and system driven by complex subjective (consumer) preferences such as the consumption patterns of urban residents targeted in this paper.

For complex systems such as urban consumption, where, as stated above CFP cannot be used for representing diverse environmental impacts, Principal Components Analysis (PCA) could be used to reduce the number of indicators from the chosen LCIA method. Recently, Lasvaux et al. (2016) shown such an analysis carried out for construction sector and concluded that reduced number of indicators in terms of principal components (which represent 90-95\% of the variance) can be obtained for each of the LCIA method using PCA.

Steinmann et al. (2016) further demonstrated a PCA combined with correlation analysis method to reduce the number of indicators and reported a large amount of redundancy in a set of 135 chosen indicators from available in LCIA methods. Out of 135 indicators, six (climate change, land use, ozone depletion, acidification and eutrophication, marine ecotoxicity terrestrial ecotoxicity) best indicators representing cumulative $92 \%$ of variance were identified. From the list of these six indicators, it is seen that CFP represents only part of the variation of the system impacts.

The finding from our study and these recent efforts shows that, it is essential to go one step further and hence beyond conventional analysis while dealing with sustainability assessment of complex systems. Methods and tools such as PCA and Multiple Criteria Decision Making (MCDM) play a critical role while providing decision support in such situations. PCA and MCDM are on the other hand complex data analysis approaches and not applicable by the average life cycle practitioner. We 
therefore suggest that techniques such as PCA and MCDM should be included in the product system modelling software and where these analyses can be performed according to a set of predefined guidelines.

\section{Acknowledgements:}

The first author acknowledges Postdoctoral fellowship received from the People Programme (Marie Curie Actions) of the European Union's Seventh Framework Programme (FP7/2007-2013) under REA grant agreement no 609405 (COFUNDPostdocDTU). We are grateful to two anonymous reviewers for providing insightful comments. We also thank Monia Niero (DTU Management Engineering) for her constructive comments and feedback on initial draft of this paper.

\section{References:}

Azapagica, A., Cliftb, R., 1999. Allocation of environmental burdens in multiple-function systems. J. Clean. Prod. 7, 101-119. doi:10.1016/S0959-6526(98)00046-8

Bao, H.P., Multani, H.S., 2007. Energy-Based Life Cycle Assessment of Industrial Procducts 123127.

Benini L., Mancini L., Sala S., Manfredi S., Schau E. M., Pant R. 2014. Normalisation method and data for Environmental Footprints. European Commission, Joint Research Center, Institute for Environment and Sustainability, Publications Office of the European Union, Luxemburg, , 26842, ISBN: 978-92-79-40847-2.

Berger, M., Finkbeiner, M., 2011. Correlation analysis of life cycle impact assessment indicators measuring resource use. Int. J. Life Cycle Assess. 16, 74-81. doi:10.1007/s11367-010-0237-7

Berthouex, P. Mac, Brown, L.C., 1994. Statistics for environmental engineers. Lewis publishers.

Bösch, M.E., Hellweg, S., Huijbregts, M. a. J., Frischknecht, R., 2007. Applying cumulative exergy demand (CExD) indicators to the ecoinvent database. Int. J. Life Cycle Assess. 12, 181-190. doi:10.1007/s11367-006-0282-4

Chen, P.Y., Popovich, P.M., 2002. Correlation: Parametric and nonparametric measures. Thousand Oaks, CA: Sage Publications.

Čuček, L., Klemeš, J.J., Kravanja, Z., 2012. A review of footprint analysis tools for monitoring impacts on sustainability. J. Clean. Prod. 34, 9-20. doi:10.1016/j.jclepro.2012.02.036

Ekvall, T., Finnveden, G., 2001. Allocation in ISO 14041-a critical review. J. Clean. Prod. 9, 197208. doi:10.1016/S0959-6526(00)00052-4

Finkbeiner, M., 2009. Carbon footprinting — opportunities and threats. Int. J. Life Cycle Assess. 14, 91-94. doi:10.1007/s11367-009-0064-х

Finnveden, G., Hauschild, M.Z., Ekvall, T., Guinée, J., Heijungs, R., Hellweg, S., Koehler, A., 
Pennington, D., Suh, S., 2009. Recent developments in Life Cycle Assessment. J. Environ. Manage. 91, 1-21. doi:10.1016/j.jenvman.2009.06.018

Goedkoop, M., Heijungs, R., Huijbregts, M. a. J., Schryver, A. De, Struijs, J., Zelm, R. Van, 2008. ReCiPe 2008, A life cycle impact assessment method which comprises harminised category indicators at the midpoint and the endpoint level, First edition, Report I: Characterisation. Available from internet http//www. lcia-recipe. net 126.

Goedkoop, M., Spriensma, R., 2001. The eco-indicator99: A damage oriented method for life cycle impact assessment: Methodology report.

Goldstein, B., Birkved, M., Quitzau, M.-B., Hauschild, M., 2013. Quantification of urban metabolism through coupling with the life cycle assessment framework: concept development and case study. Environ. Res. Lett. 8, 35024. doi:10.1088/1748-9326/8/3/035024

Guinée, J.B., Heijungs, R., Huppes, G., Kleijn, R., de Koning, a., van Oers, L., Wegener Sleeswijk, a., Suh, S., Udo de Haes, H. a., de Bruijn, H., van Duin, R., Huijbregts, M. a. J., Gorrée, M., 2001. Life Cycle Assessment: An Operational Guide to the ISO Standards. Netherlands Minist. ... 692. doi:10.1007/BF02978784

Guinée, J.B., Heijungs, R., Huppes, G., Zamagni, A., Masoni, P., Buonamici, R., Ekvall, T., Rydberg, T., 2011. Life cycle assessment: past, present, and future. Environ. Sci. Technol. 45, 90-96. doi:10.1021/es101316v

Hauschild, M.Z., Goedkoop, M., Guinée, J., Heijungs, R., Huijbregts, M., Jolliet, O., Margni, M., De Schryver, A., Humbert, S., Laurent, A., Sala, S., Pant, R., 2013. Identifying best existing practice for characterization modeling in life cycle impact assessment. Int. J. Life Cycle Assess. 18, 683-697. doi:10.1007/s11367-012-0489-5

Hauschild, M.Z., Wenzel, H., Alting, L., 1998. Environmental assessment of products (Vol. 2). Scientific background.

Hellweg, S., Milà i Canals, L., 2014. Emerging approaches, challenges and opportunities in life cycle assessment. Science 344, 1109-13. doi:10.1126/science.1248361

Herva, M., Franco, A., Carrasco, E.F., Roca, E., 2011. Review of corporate environmental indicators. J. Clean. Prod. 19, 1687-1699. doi:10.1016/j.jclepro.2011.05.019

Huijbregts, M. a J., Hellweg, S., Frischknecht, R., Hendriks, H.W.M., Hungehbühler, K., Hendriks, a. J., 2010. Cumulative Energy Demand As Predictor for the Environmental Burden of Commodity Production. Environ. Sci. Technol. 44, 2189-2196. doi:10.1021/es902870s

Kalbar, P.P., Birkved, M., Kabins, S., Nygaard, S.E., 2016. Personal-Metabolism (PM) coupled with Life Cycle Assessment (LCA) Model: Danish Case Study. Environ. Int. 91, 168-179. doi:10.1016/j.envint.2016.02.032

Lasvaux, S., Achim, F., Garat, P., Peuportier, B., Chevalier, J., Habert, G., 2016. Correlations in Life Cycle Impact Assessment methods (LCIA) and indicators for construction materials: What matters? Ecol. Indic. 67, 174-182. doi:10.1016/j.ecolind.2016.01.056

Laurent, A., Olsen, S.I., Hauschild, M.Z., 2012. Limitations of carbon footprint as indicator of environmental sustainability. Environ. Sci. Technol. 46, 4100-4108. doi:10.1021/es204163f

Laurent, A., Olsen, S.I., Hauschild, M.Z., 2010. Carbon footprint as environmental performance indicator for the manufacturing industry. CIRP Ann. - Manuf. Technol. 59, 37-40. 
doi:10.1016/j.cirp.2010.03.008

PE International, 2012. PE LCIA Survey 2012 (Weighting). http://database-documentation.gabisoftware.com/america/support/gabi/gabi-lcia-documentation/pe-lcia-survey-2012-weighting/.

Pennington, D.W., Potting, J., Finnveden, G., Lindeijer, E., Jolliet, O., Rydberg, T., Rebitzer, G., 2004. Life cycle assessment Part 2: Current impact assessment practice. Environ. Int. 30, 721739. doi:10.1016/j.envint.2003.12.009

Reap, J., Roman, F., Duncan, S., Bras, B., 2008a. A survey of unresolved problems in life cycle assessment. Part 1 : goal and scope and inventory analysis 290-300. doi:10.1007/s11367-0080008-X

Reap, J., Roman, F., Duncan, S., Bras, B., 2008b. A survey of unresolved problems in life cycle assessment. Part 2: Impact assessment and interpretation. Int. J. Life Cycle Assess. 13, 374388. doi:10.1007/s11367-008-0009-9

Rebitzer, G., Ekvall, T., Frischknecht, R., Hunkeler, D., Norris, G., Rydberg, T., Schmidt, W.P., Suh, S., Weidema, B.P., Pennington, D.W., 2004. Life cycle assessment Part 1: Framework, goal and scope definition, inventory analysis, and applications. Environ. Int. 30, 701-720. doi:10.1016/j.envint.2003.11.005

Reimann, C., Filzmoser, P., Garrett, R., Dutter, R., 2011. Statistical data analysis explained: applied environmental statistics with R. John Wiley \& Sons.

Röös, E., Sundberg, C., Tidåker, P., Strid, I., Hansson, P.A., 2013. Can carbon footprint serve as an indicator of the environmental impact of meat production ? Ecol. Indic. 24, 573-581. doi:10.1016/j.ecolind.2012.08.004

Rugani, B., Vázquez-Rowe, I., Benedetto, G., Benetto, E., 2013. A comprehensive review of carbon footprint analysis as an extended environmental indicator in the wine sector. J. Clean. Prod. 54, 61-77. doi:10.1016/j.jclepro.2013.04.036

Singh, R.K., Murty, H.R., Gupta, S.K., Dikshit, A.K., 2009. An overview of sustainability assessment methodologies. Ecol. Indic. 9, 189-212. doi:10.1016/j.ecolind.2008.05.011

Spiegel, M.R., Stephens, L.J., 2007. Schaum’s Outline of Statistics. Schaum’s Outline Series. The McGraw-Hill Companies Inc., U.S.A.

Steinmann, Z.J.N., Schipper, A.M., Hauck, M., Huijbregts, M.A.J., 2016. How Many Environmental Impact Indicators Are Needed in the Evaluation of Product Life Cycles? Environ. Sci. Technol. 50, 3913-3919. doi:10.1021/acs.est.5b05179

Suh, S., 2006. Critical Review System Boundary Selection in Life-Cycle Inventories Using Hybrid Approaches. Environ. Sci. Technol. 38, 657-664.

Tillman, A.M., Ekvall, T., Baumann, H., Rydberg, T., 1998. Choice of system boundaries in life cycle assessment. Doktorsavhandlingar vid Chalmers Tek. Hogsk. 2, 21-29. doi:10.1016/0959-6526(94)90021-3

Udo de Haes, H.A., 2006. Life-Cycle Assessment and the Use of Broad Indicators. J. Ind. Ecol. 10, 5-7. doi:10.1162/jiec.2006.10.3.5

Udo de Haes, H.A., Heijungs, R., Suh, S., Huppes, G., 2004. Three Strategies to Overcome the Limitations of Life-Cycle Assessment. J. Ind. Ecol. 8, 19-32. doi:10.1162/1088198042442351 
Van Hoof, G., Vieira, M., Gausman, M., Weisbrod, A., 2013. Indicator selection in life cycle assessment to enable decision making: Issues and solutions. Int. J. Life Cycle Assess. 18, 1568-1580. doi:10.1007/s11367-013-0595-z

Weidema, B.P., Thrane, M., Christensen, P., Schmidt, J., Løkke, S., 2008. Carbon Footprint A Catalyst for Life Cycle Assessment? J. Ind. Ecol. 12, 3-6. doi:10.1111/j.15309290.2008.00005.x

Wenzel, H., Hauschild, M., Alting, L., 1997. Environmental assessment of products, vol. 1: Methodology, tools and case studies in product development. Institute of Product Development. 


\section{Supporting Information}

for

\section{Can carbon footprint serve as proxy of the environmental burden from urban consumption patterns?}

Pradip P. Kalbar ${ }^{* \#}$, Morten Birkved ${ }^{1}$, Subhankar Karmakar²,3,4 , Simon Elsborg Nygaard $^{5}$, and Michael Hauschild ${ }^{1}$

${ }^{1}$ Quantitative Sustainability Assessment Division, Department of Management Engineering, Technical University of Denmark (DTU), Produktionstorvet 424, DK-2800 Kgs. Lyngby, Denmark

${ }^{2}$ Centre for Environmental Science and Engineering, Indian Institute of Technology Bombay, Powai, Mumbai 400 076, India.

${ }^{3}$ Interdisciplinary Programme in Climate Studies, Indian Institute of Technology Bombay, Mumbai 400076. India.

${ }^{4}$ Centre for Urban Science and Engineering, Indian Institute of Technology Bombay, Powai, Mumbai 400 076, India.

${ }^{5}$ Department of Psychology and Behavioural Sciences, BSS, Aarhus University, Denmark

\# Corresponding author:

Pradip P. Kalbar

Quantitative Sustainability Assessment Division

Dept. of Management Engineering

Technical University of Denmark (DTU)

Produktionstorvet

Building 424, room 231

2800 Kgs. Lyngby

Denmark

Tel. No.+45 45254607

Email Address: kalbar@iitb.ac.in; pradipkalbar@gmail.com

*Present affiliation: Centre for Urban Science and Engineering, Indian Institute of Technology Bombay, Powai, Mumbai 400 076, India 


\section{Contents:}

Figure S1: Correlation graphs showing effect of aggregation on the correlation between CFP and other impact indicators at the total consumption level.

Table S1: Results of correlation analysis between the ReCiPe Carbon Footprint (CFP) and the additional indicators considered in our study. Page S4

Table S2: Result of interdependence study - Correlation among indicators of each consumption component Page S7 


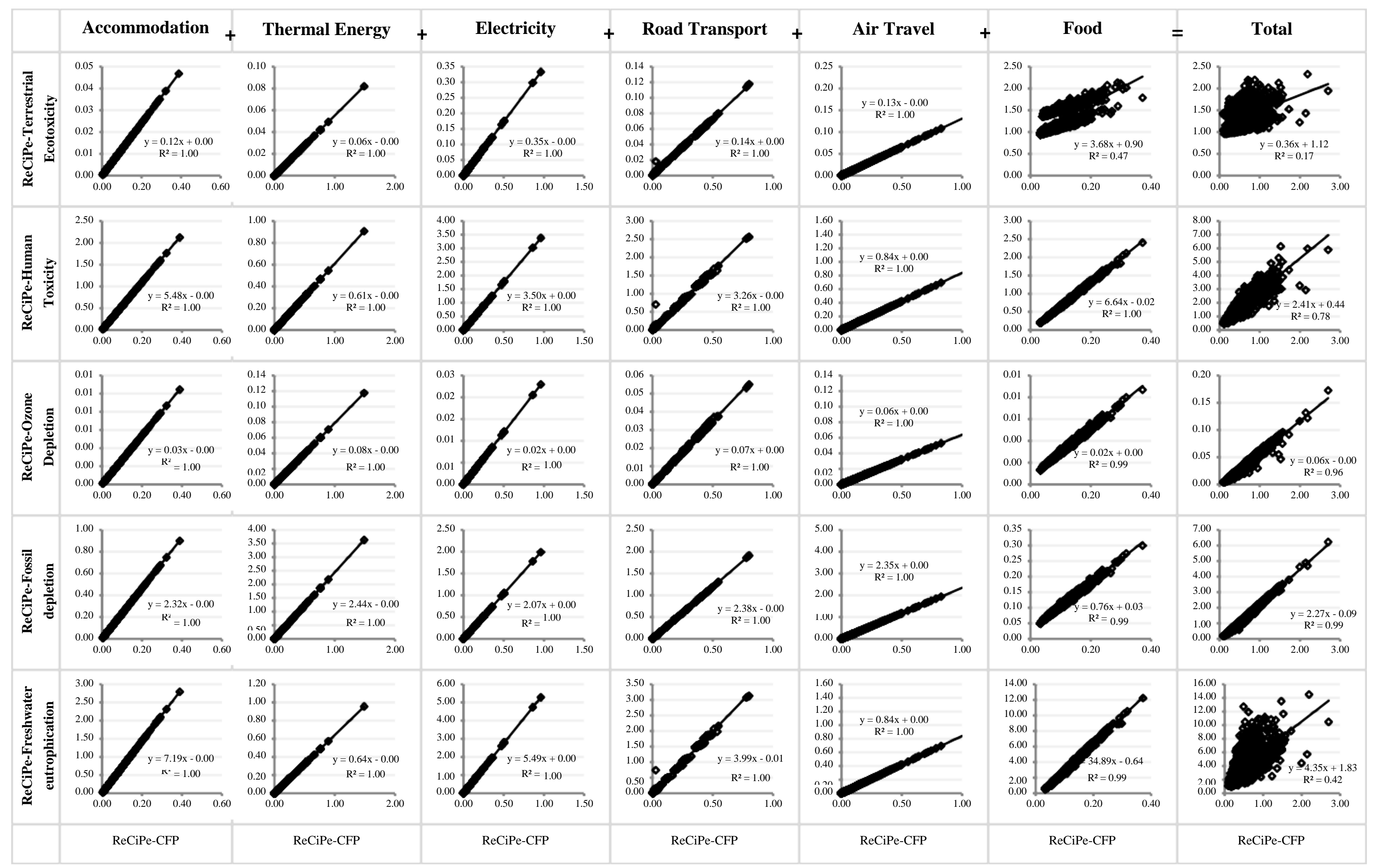

Figure S1: Correlation graphs showing effect of aggregation on the correlation between CFP and other impact indicators at the total consumption level. 
Table S1: Results of correlation analysis between the ReCiPe Carbon Footprint (CFP) and the additional indicators considered in our study at the level of individual consumption components and for the total consumption.

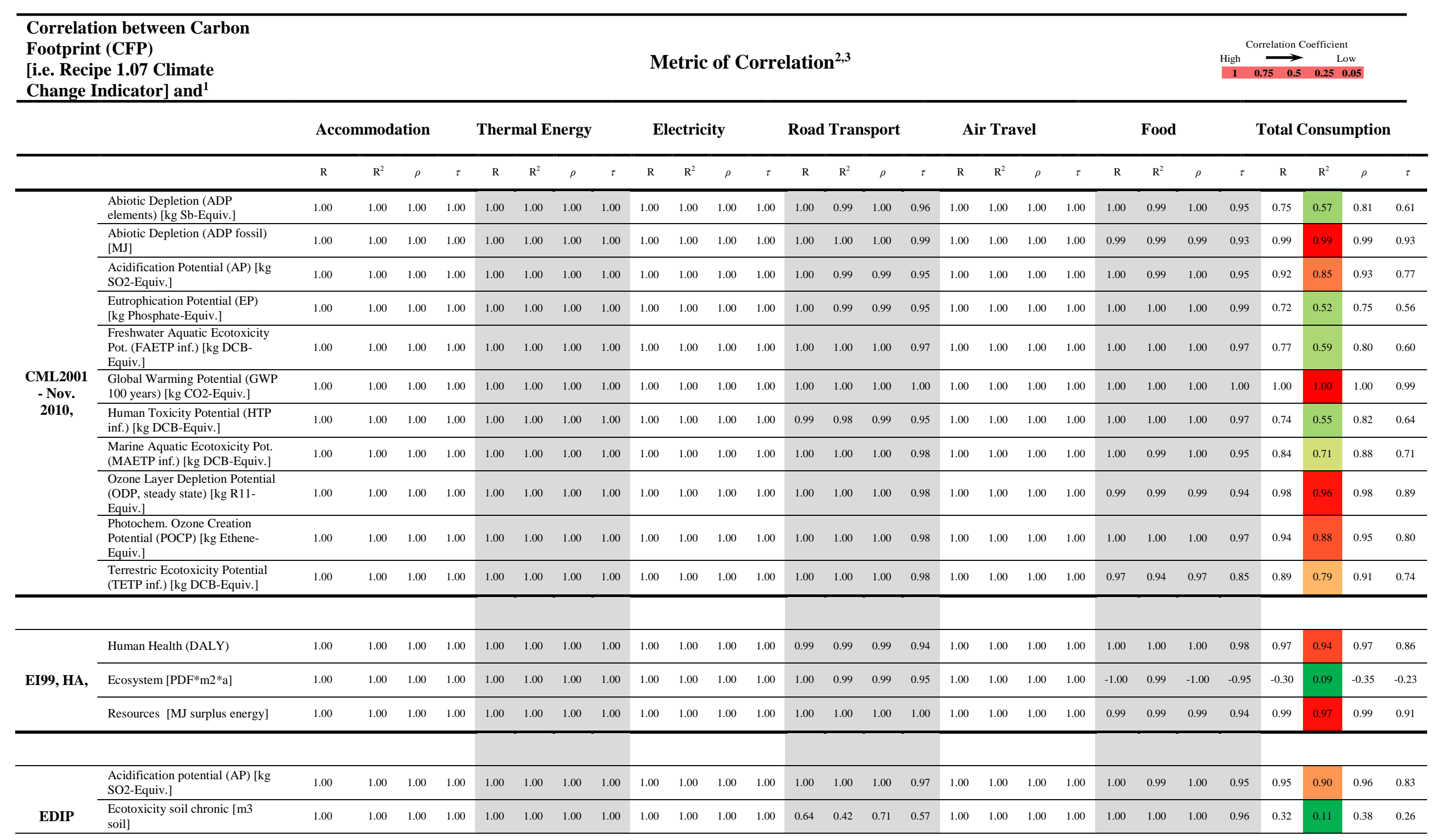




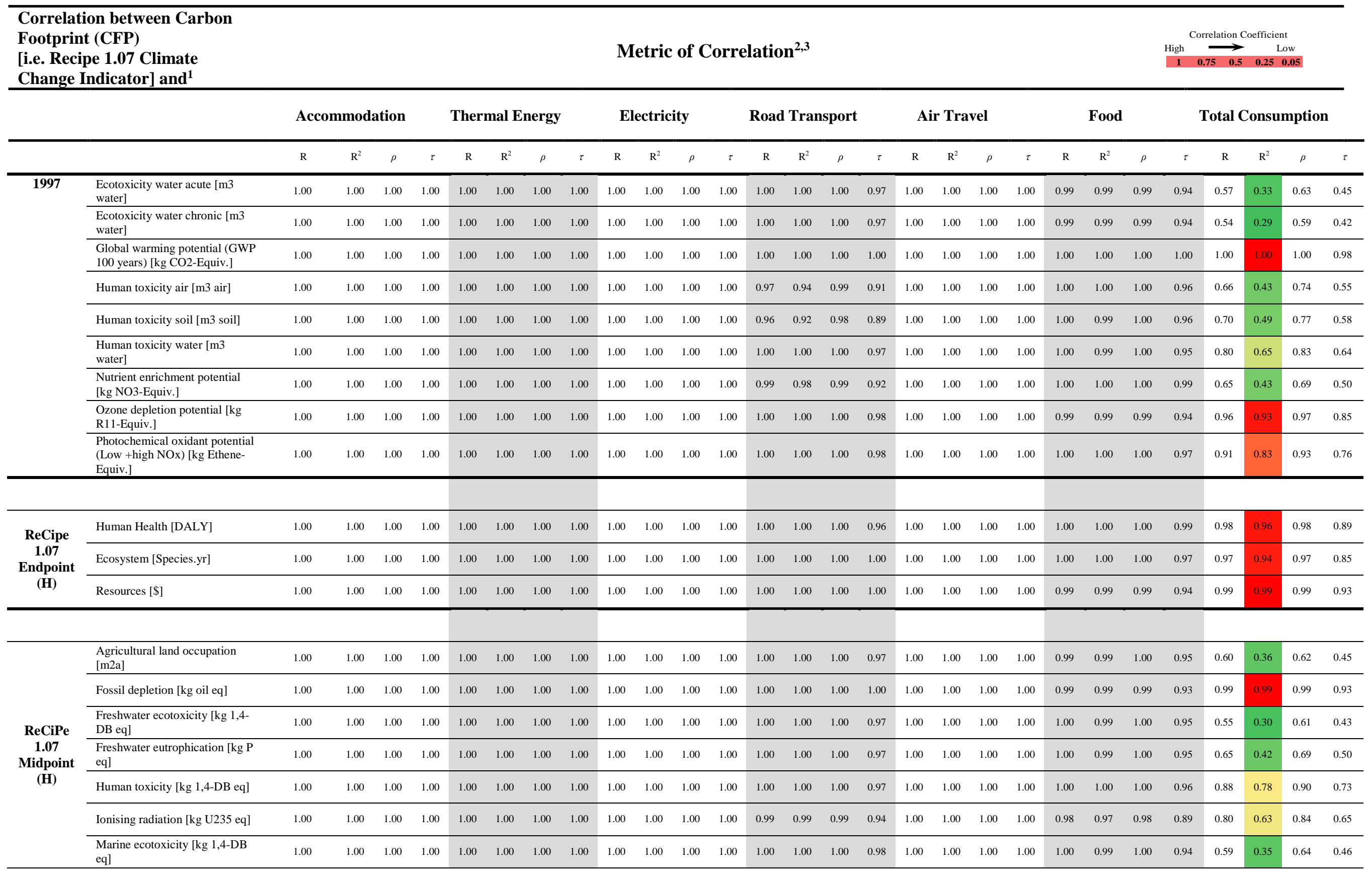




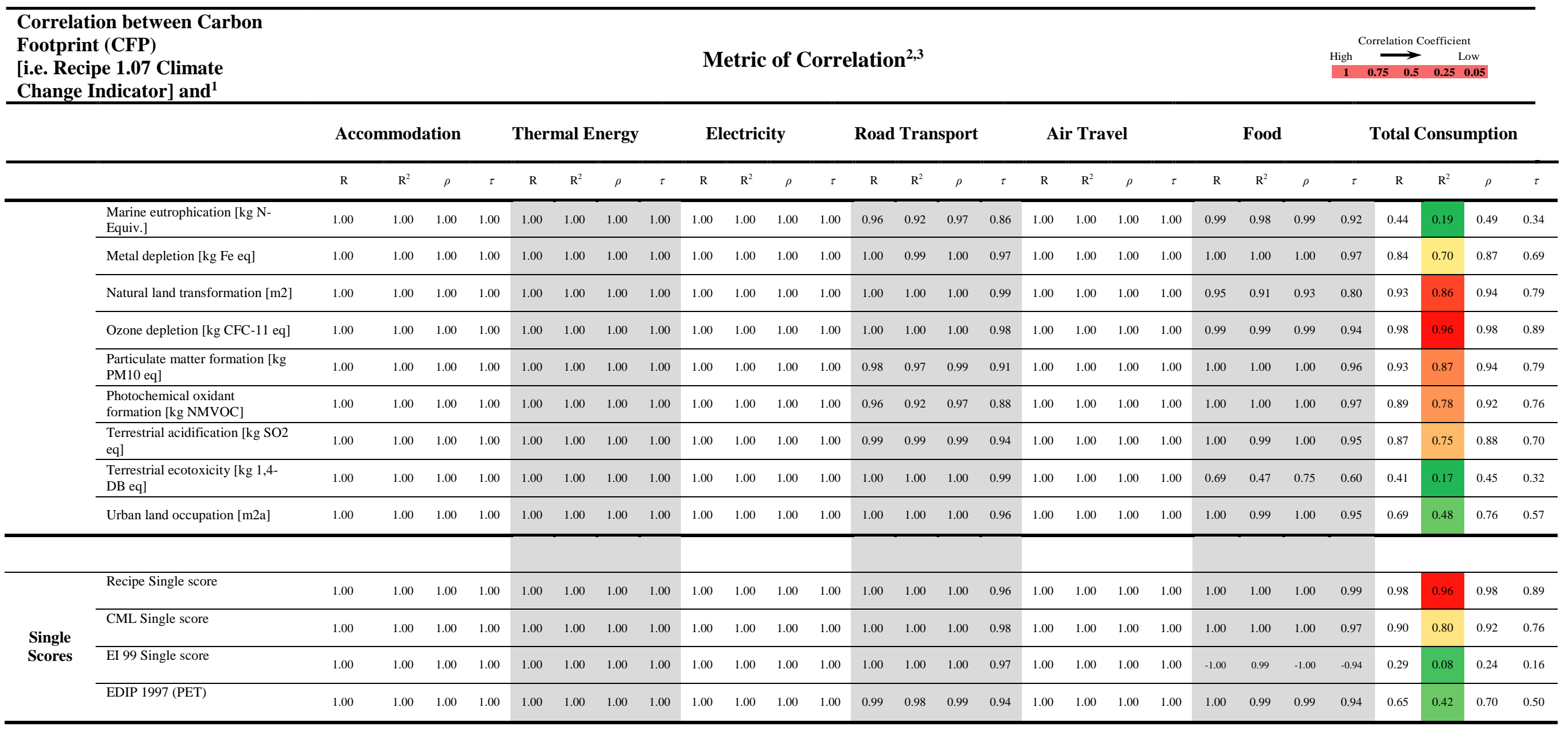

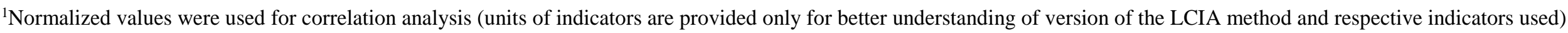

${ }^{2}$ Pearson Correlation Coefficient $(R)$ and Coefficeint of Determination $\left(R^{2}\right)$, Sperman's rho rank correlation coefficient ( $\left.\rho\right)$ and Kendall's tau rank correlation coefficient $(\tau)$

${ }^{3}$ All the correlation values reported in this table are significant at 0.01 level. 
Table S2: Result of interdependence study - Correlation among indicators of each consumption component Pearson Correlation Coefficent; Coefficeint of Determination $\left(R^{2}\right)$; Sperman's rank correlation coefficient $(\rho)$ and Kendall's rank correlation coefficient $(\tau)$

\#indicates the correlation not significant at 0.01 level.

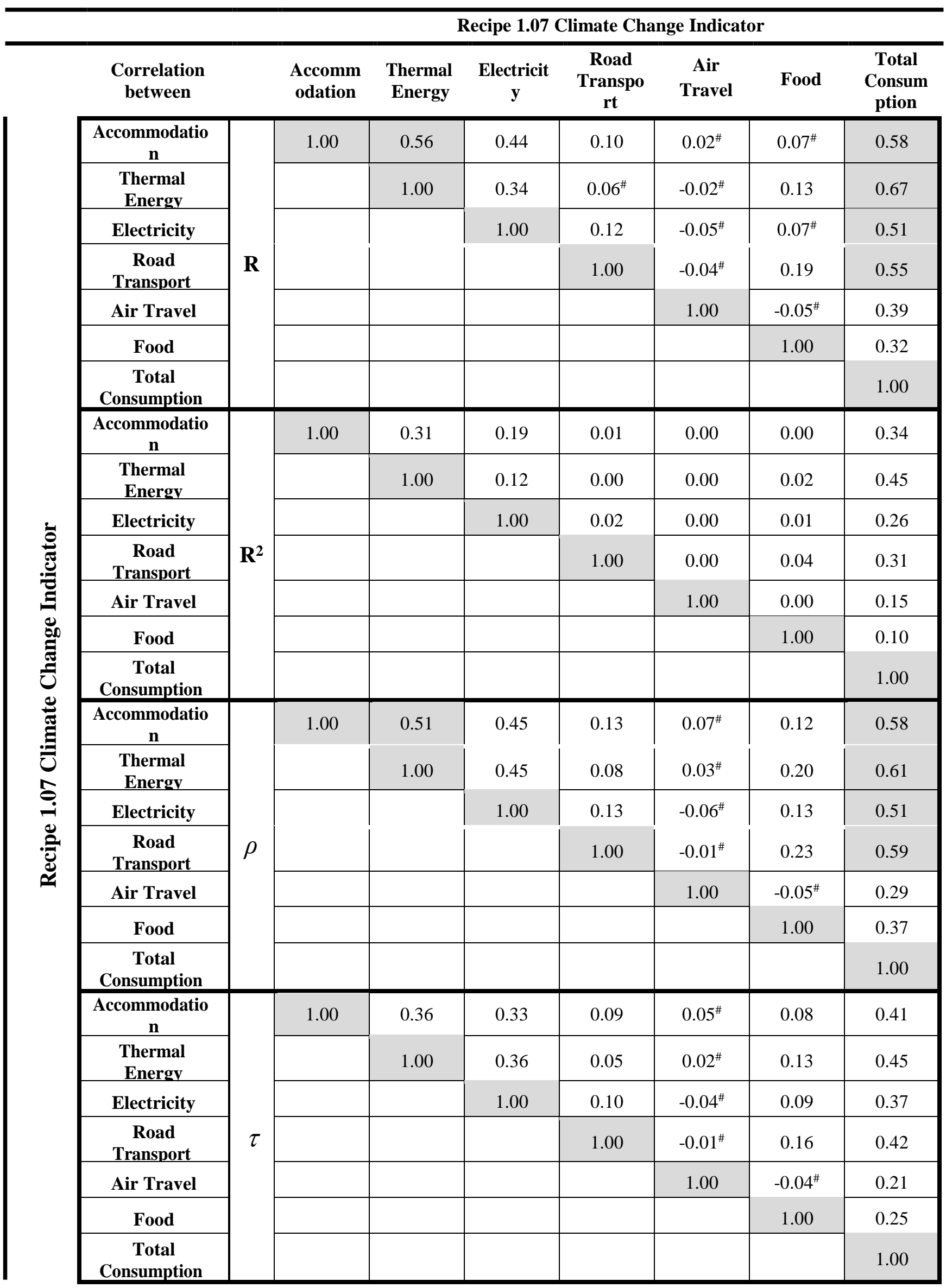


Recipe 1.07 Freshwater Eutrophication

Correlation between
Accomm Thermal odation Energy
Road

Transpo
Total

Consum

ption

\begin{tabular}{|c|c|c|c|c|c|c|c|c|}
\hline $\begin{array}{c}\text { Accommodatio } \\
\mathbf{n}\end{array}$ & \multirow{7}{*}{$\mathbf{R}$} & 1.00 & 0.56 & 0.44 & 0.10 & $0.02^{\#}$ & $0.06^{\#}$ & 0.35 \\
\hline $\begin{array}{c}\text { Thermal } \\
\text { Energy }\end{array}$ & & & 1.00 & 0.34 & $0.06^{\#}$ & $-0.02^{\#}$ & 0.12 & 0.32 \\
\hline Electricity & & & & 1.00 & 0.12 & $-0.05^{\#}$ & $0.06^{\#}$ & 0.36 \\
\hline $\begin{array}{c}\text { Road } \\
\text { Transport }\end{array}$ & & & & & 1.00 & $-0.04^{\#}$ & 0.18 & 0.47 \\
\hline Air Travel & & & & & & 1.00 & $-0.04^{\#}$ & $0.00^{\#}$ \\
\hline Food & & & & & & & 1.00 & 0.89 \\
\hline $\begin{array}{c}\text { Total } \\
\text { Consumption } \\
\end{array}$ & & & & & & & & 1.00 \\
\hline $\begin{array}{c}\text { Accommodatio } \\
\mathbf{n}\end{array}$ & \multirow{7}{*}{$\mathbf{R}^{2}$} & 1.00 & 0.31 & 0.19 & 0.01 & 0.00 & 0.00 & 0.12 \\
\hline $\begin{array}{l}\text { Thermal } \\
\text { Energy }\end{array}$ & & & 1.00 & 0.12 & 0.00 & 0.00 & 0.02 & 0.10 \\
\hline Electricity & & & & 1.00 & 0.01 & 0.00 & 0.00 & 0.13 \\
\hline $\begin{array}{c}\text { Road } \\
\text { Transport }\end{array}$ & & & & & 1.00 & 0.00 & 0.03 & 0.22 \\
\hline Air Travel & & & & & & 1.00 & 0.00 & 0.00 \\
\hline Food & & & & & & & 1.00 & 0.80 \\
\hline $\begin{array}{c}\text { Total } \\
\text { Consumption }\end{array}$ & & & & & & & & 1.00 \\
\hline $\begin{array}{c}\text { Accommodatio } \\
\mathbf{n} \\
\end{array}$ & \multirow{7}{*}{$\rho$} & 1.00 & 0.51 & 0.45 & 0.13 & $0.07^{\#}$ & 0.11 & 0.37 \\
\hline $\begin{array}{c}\text { Thermal } \\
\text { Energy }\end{array}$ & & & 1.00 & 0.45 & 0.08 & $0.03^{\#}$ & 0.19 & 0.34 \\
\hline Electricity & & & & 1.00 & 0.13 & $-0.06^{\#}$ & 0.12 & 0.37 \\
\hline $\begin{array}{c}\text { Road } \\
\text { Transport } \\
\end{array}$ & & & & & 1.00 & $-0.01^{\#}$ & 0.23 & 0.50 \\
\hline Air Travel & & & & & & 1.00 & $-0.05^{\#}$ & $-0.01^{\#}$ \\
\hline Food & & & & & & & 1.00 & 0.88 \\
\hline $\begin{array}{c}\text { Total } \\
\text { Consumption } \\
\end{array}$ & & & & & & & & 1.00 \\
\hline $\begin{array}{c}\text { Accommodatio } \\
\mathbf{n} \\
\end{array}$ & \multirow{7}{*}{$\tau$} & 1.00 & 0.36 & 0.33 & 0.09 & $0.05^{\#}$ & 0.07 & 0.25 \\
\hline $\begin{array}{c}\text { Thermal } \\
\text { Energy }\end{array}$ & & & 1.00 & 0.36 & 0.06 & $0.02^{\#}$ & 0.13 & 0.23 \\
\hline Electricity & & & & 1.00 & 0.10 & $-0.04^{\#}$ & 0.08 & 0.26 \\
\hline $\begin{array}{c}\text { Road } \\
\text { Transport }\end{array}$ & & & & & 1.00 & $0.00^{\#}$ & 0.15 & 0.34 \\
\hline Air Travel & & & & & & 1.00 & $-0.04^{\#}$ & $0.00^{\#}$ \\
\hline Food & & & & & & & 1.00 & 0.70 \\
\hline $\begin{array}{c}\text { Total } \\
\text { Consumption }\end{array}$ & & & & & & & & 1.00 \\
\hline
\end{tabular}


Recipe 1.07 Terrestrial Ecotoxicity

Correlation between
Accomm Thermal odation Energy
Road

Transpo
Air Travel
Total

Food Consum

ption

\begin{tabular}{|c|c|c|c|c|c|c|c|c|}
\hline $\begin{array}{c}\text { Accommodatio } \\
\text { n }\end{array}$ & \multirow{7}{*}{$\mathbf{R}$} & 1.00 & 0.56 & 0.44 & 0.10 & $0.02^{\#}$ & 0.07 & 0.16 \\
\hline $\begin{array}{c}\text { Thermal } \\
\text { Energy } \\
\end{array}$ & & & 1.00 & 0.34 & $0.06^{\#}$ & $-0.02^{\#}$ & 0.13 & 0.20 \\
\hline Electricity & & & & 1.00 & 0.12 & $-0.05^{\#}$ & $0.06^{\#}$ & 0.18 \\
\hline $\begin{array}{c}\text { Road } \\
\text { Transport } \\
\end{array}$ & & & & & 1.00 & $-0.04^{\#}$ & 0.24 & 0.32 \\
\hline Air Travel & & & & & & 1.00 & $-0.06^{\#}$ & $0.00^{\#}$ \\
\hline Food & & & & & & & 1.00 & 0.99 \\
\hline $\begin{array}{c}\text { Total } \\
\text { Consumption }\end{array}$ & & & & & & & & 1.00 \\
\hline $\begin{array}{c}\text { Accommodatio } \\
\text { n }\end{array}$ & \multirow{7}{*}{$\mathbf{R}^{2}$} & 1.00 & 0.31 & 0.19 & 0.01 & 0.00 & 0.01 & 0.03 \\
\hline $\begin{array}{l}\text { Thermal } \\
\text { Energy }\end{array}$ & & & 1.00 & 0.12 & 0.00 & 0.00 & 0.02 & 0.04 \\
\hline Electricity & & & & 1.00 & 0.02 & 0.00 & 0.00 & 0.03 \\
\hline $\begin{array}{c}\text { Road } \\
\text { Transport }\end{array}$ & & & & & 1.00 & 0.00 & 0.06 & 0.10 \\
\hline Air Travel & & & & & & 1.00 & 0.00 & 0.00 \\
\hline Food & & & & & & & 1.00 & 0.97 \\
\hline $\begin{array}{c}\text { Total } \\
\text { Consumption }\end{array}$ & & & & & & & & 1.00 \\
\hline $\begin{array}{c}\text { Accommodatio } \\
\mathbf{n}\end{array}$ & \multirow{7}{*}{$\rho$} & 1.00 & 0.51 & 0.45 & 0.13 & $0.07^{\#}$ & 0.10 & 0.19 \\
\hline $\begin{array}{c}\text { Thermal } \\
\text { Energy }\end{array}$ & & & 1.00 & 0.45 & 0.08 & $0.03^{\#}$ & 0.17 & 0.23 \\
\hline Electricity & & & & 1.00 & 0.13 & $-0.06^{\#}$ & 0.11 & 0.22 \\
\hline $\begin{array}{c}\text { Road } \\
\text { Transport } \\
\end{array}$ & & & & & 1.00 & $-0.01^{\#}$ & 0.25 & 0.34 \\
\hline Air Travel & & & & & & 1.00 & -0.08 & $-0.04^{\#}$ \\
\hline Food & & & & & & & 1.00 & 0.98 \\
\hline $\begin{array}{c}\text { Total } \\
\text { Consumption } \\
\end{array}$ & & & & & & & & 1.00 \\
\hline $\begin{array}{c}\text { Accommodatio } \\
\mathbf{n} \\
\end{array}$ & \multirow{7}{*}{$\tau$} & 1.00 & 0.36 & 0.33 & 0.09 & $0.05^{\#}$ & 0.07 & 0.13 \\
\hline $\begin{array}{c}\text { Thermal } \\
\text { Energy }\end{array}$ & & & 1.00 & 0.36 & 0.05 & $0.02^{\#}$ & 0.12 & 0.16 \\
\hline Electricity & & & & 1.00 & 0.10 & $-0.04^{\#}$ & 0.08 & 0.15 \\
\hline $\begin{array}{c}\text { Road } \\
\text { Transport }\end{array}$ & & & & & 1.00 & $-0.01^{\#}$ & 0.17 & 0.23 \\
\hline Air Travel & & & & & & 1.00 & -0.06 & $-0.02^{\#}$ \\
\hline Food & & & & & & & 1.00 & 0.89 \\
\hline $\begin{array}{c}\text { Total } \\
\text { Consumption }\end{array}$ & & & & & & & & 1.00 \\
\hline
\end{tabular}


Recipe 1.07 Human Toxicity

Correlation between

Accomm Thermal Electricit Road Air

Transpo Travel

Total odation Energy

y rt

Food Consum

ption

\begin{tabular}{|c|c|c|c|c|c|c|c|c|}
\hline $\begin{array}{c}\text { Accommodatio } \\
\text { n }\end{array}$ & \multirow{7}{*}{$\mathbf{R}$} & 1.00 & 0.56 & 0.44 & 0.10 & $0.02^{\#}$ & $0.06^{\#}$ & 0.58 \\
\hline $\begin{array}{c}\text { Thermal } \\
\text { Energy }\end{array}$ & & & 1.00 & 0.34 & $0.06^{\#}$ & $-0.02^{\#}$ & 0.13 & 0.45 \\
\hline Electricity & & & & 1.00 & 0.12 & $-0.05^{\#}$ & $0.07^{\#}$ & 0.56 \\
\hline $\begin{array}{c}\text { Road } \\
\text { Transport }\end{array}$ & & & & & 1.00 & $-0.04^{\#}$ & 0.19 & 0.70 \\
\hline Air Travel & & & & & & 1.00 & $-0.04^{\#}$ & 0.08 \\
\hline Food & & & & & & & 1.00 & 0.53 \\
\hline $\begin{array}{c}\text { Total } \\
\text { Consumption } \\
\end{array}$ & & & & & & & & 1.00 \\
\hline $\begin{array}{c}\text { Accommodatio } \\
n\end{array}$ & \multirow{7}{*}{$\mathbf{R}^{2}$} & 1.00 & 0.31 & 0.19 & 0.01 & 0.00 & 0.00 & 0.33 \\
\hline $\begin{array}{c}\text { Thermal } \\
\text { Energy }\end{array}$ & & & 1.00 & 0.12 & 0.00 & 0.00 & 0.02 & 0.21 \\
\hline Electricity & & & & 1.00 & 0.01 & 0.00 & 0.00 & 0.31 \\
\hline $\begin{array}{c}\text { Road } \\
\text { Transport } \\
\end{array}$ & & & & & 1.00 & 0.00 & 0.04 & 0.49 \\
\hline Air Travel & & & & & & 1.00 & 0.00 & 0.01 \\
\hline Food & & & & & & & 1.00 & 0.29 \\
\hline $\begin{array}{c}\text { Total } \\
\text { Consumption }\end{array}$ & & & & & & & & 1.00 \\
\hline$\underset{n}{\text { Accommodatio }}$ & \multirow{7}{*}{$\rho$} & 1.00 & 0.51 & 0.45 & 0.13 & $0.07^{\#}$ & 0.12 & 0.55 \\
\hline $\begin{array}{c}\text { Thermal } \\
\text { Energy }\end{array}$ & & & 1.00 & 0.45 & 0.08 & $0.03^{\#}$ & 0.19 & 0.43 \\
\hline Electricity & & & & 1.00 & 0.13 & $-0.06^{\#}$ & 0.12 & 0.51 \\
\hline $\begin{array}{c}\text { Road } \\
\text { Transport }\end{array}$ & & & & & 1.00 & $-0.01^{\#}$ & 0.23 & 0.71 \\
\hline Air Travel & & & & & & 1.00 & $-0.05^{\#}$ & $0.06^{\#}$ \\
\hline Food & & & & & & & 1.00 & 0.56 \\
\hline $\begin{array}{c}\text { Total } \\
\text { Consumption }\end{array}$ & & & & & & & & 1.00 \\
\hline $\begin{array}{c}\text { Accommodatio } \\
n\end{array}$ & \multirow{7}{*}{$\tau$} & 1.00 & 0.36 & 0.33 & 0.09 & $0.05^{\#}$ & 0.08 & 0.39 \\
\hline $\begin{array}{c}\text { Thermal } \\
\text { Energy }\end{array}$ & & & 1.00 & 0.36 & 0.06 & $0.02^{\#}$ & 0.13 & 0.31 \\
\hline Electricity & & & & 1.00 & 0.10 & $-0.04^{\#}$ & 0.09 & 0.37 \\
\hline $\begin{array}{c}\text { Road } \\
\text { Transport }\end{array}$ & & & & & 1.00 & $0.00^{\#}$ & 0.16 & 0.51 \\
\hline Air Travel & & & & & & 1.00 & $-0.04^{\#}$ & $0.04^{\#}$ \\
\hline Food & & & & & & & 1.00 & 0.40 \\
\hline $\begin{array}{c}\text { Total } \\
\text { Consumption }\end{array}$ & & & & & & & & 1.00 \\
\hline
\end{tabular}

